\title{
BEHAVIOURAL CONSEQUENCES OF UNILATERAL INFERIOR COLLICULUS LESIONS IN THE RAT
}

\author{
By: Aaron James Burke \\ Thesis submitted to the Faculty of Graduate and Postdoctoral Affairs \\ In partial fulfillment of the requirements for the degree of: \\ Master of Science, Specialization in Behavioural Neuroscience, \\ Department of Psychology
}

Carleton University,

Ottawa, ON

CAaron James Burke 


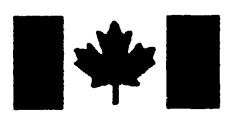

\section{Library and Archives \\ Canada \\ Published Heritage \\ Branch \\ 395 Wellington Street Ottawa ON K1A ON4 Canada}

Bibliothèque et

Archives Canada

Direction du

Patrimoine de l'édition

395, rue Wellington

Ottawa ON K1A ON4

Canada
Your file Votre référence
ISBN: $978-0-494-71573-4$
Our file Notre référence
ISBN: $978-0-494-71573-4$
NOTICE:

The author has granted a nonexclusive license allowing Library and Archives Canada to reproduce, publish, archive, preserve, conserve, communicate to the public by telecommunication or on the Internet, loan, distribute and sell theses worldwide, for commercial or noncommercial purposes, in microform, paper, electronic and/or any other formats.

The author retains copyright ownership and moral rights in this thesis. Neither the thesis nor substantial extracts from it may be printed or otherwise reproduced without the author's permission.
AVIS:

L'auteur a accordé une licence non exclusive permettant à la Bibliothèque et Archives Canada de reproduire, publier, archiver, sauvegarder, conserver, transmettre au public par télécommunication ou par l'Internet, prêter, distribuer et vendre des thèses partout dans le monde, à des fins commerciales ou autres, sur support microforme, papier, électronique et/ou autres formats.

L'auteur conserve la propriété du droit d'auteur et des droits moraux qui protège cette thèse. $\mathrm{Ni}$ la thèse ni des extraits substantiels de celle-ci ne doivent être imprimés ou autrement reproduits sans son autorisation.
In compliance with the Canadian Privacy Act some supporting forms may have been removed from this thesis.

While these forms may be included in the document page count, their removal does not represent any loss of content from the thesis.
Conformément à la loi canadienne sur la protection de la vie privée, quelques formulaires secondaires ont été enlevés de cette thèse.

Bien que ces formulaires aient inclus dans la pagination, il n'y aura aucun contenu manquant.

\section{Canadä}




\begin{abstract}
The purpose of this study was to determine the absolute threshold for hearing in normal rats and rats with unilateral lesions of the inferior colliculus (IC). Lesions of IC were made either ipsilateral or contralateral to one ear in animals that were deafened by a conductive ear block in the opposite ear. Two weeks following surgery, young adult male albino rats (300-350 g) were trained and tested for their ability to detect $200 \mathrm{~ms}$ broadband white noise bursts at various sound pressure levels. The water-deprived subjects were trained to obtain their daily water requirements from a spout located in a small test cage inside a large sound attenuated chamber. The animals were then conditioned to avoid a shock delivered through the spout by detecting the presence of a noise burst. The intensity of the sound was gradually reduced to obtain psychophysical curves and behavioural thresholds in each subject. Each animal was capable of performing the conditioned avoidance task. However, animals with lesions that completely destroyed the contralateral ascending projection pathways had a large elevation in threshold compared to those with equivalent lesions of the ipsilateral projection pathways or animals with no IC lesion. Further, contralateral lesions that included the dorsal nucleus of the lateral lemniscus produced an even greater elevation in threshold indicating that this structure also contributes to auditory sensitivity. Following behavioural assessment, the anatomical pathways of each animal were assessed by iontophoretic injection of Fluoro-Gold (FG) into the intact IC. The results showed the pattern of FG labeling in the lower auditory brainstem was similar to that found in normal animals.
\end{abstract}




\section{Acknowledgements}

I would like to express my gratitude to my supervisor, Dr. Jack B. Kelly. Dr. Kelly has guided my research since my undergraduate work in his laboratory. He has shared his wealth of knowledge of the auditory system, affording me greater insight to this fascinating area of research. Cheers. A special thank you to Dr. Shu Hui Wu for all of her assistance and instruction about the central auditory system, and for the many enlightening discussions we shared.

To the faculty in the Institute of Neuroscience and Department of Psychology, thank you for your support and help in shaping my rewarding experience at Carleton University.

To all members of our laboratory; especially Jean Liu and Barbara Deren, thank you for making every single day cheerful, and sharing many laughs. To my classmates, and the staff of the Life Sciences Research Building, thank you for making my studies and time spent in the laboratory memorable.

To Dr. Miyako Hatano, who motivated me, helped to refine my technical skills and more importantly became my friend, arigato gozaimasu.

I would like to show my appreciation for numerous people outside of the lab; especially my grandmother, my parents and my friends for their support, patience and love.

Finally a special thank you to my best friend and the love of my life, Amber, who inspires me, supports me, and pushes me to achieve whatever goals I set.

Thank you all! 


\section{Table of Contents}

Abstract

Acknowledgements

ii

Table of Contents

List of Abbreviations

List of Tables

List of Figures

iii

iv

vi

vii

viii

1. Introduction

1.1 The Inferior Colliculus (IC) 1

1.2 Subdivisions of the IC 2

1.3 Central Nucleus of the Inferior Colliculus (ICc) 3

1.3.1 Afferent Projections (Ascending) 3

1.3.2 CN Projections to ICc 4

1.3.3 SOC Projections to ICc 5

1.3.4 nLL Projections to ICc 7

1.3.5 Monaural and Binaural Pathways 8

1.3.6 Efferent Projections (Ascending) from ICc 9

1.3.7 Neuronal Organization of the ICc 10

$\begin{array}{ll}1.4 \text { Behavioural Studies } & 12\end{array}$

$\begin{array}{ll}\text { 2. Purpose } & 14\end{array}$

3. Materials and Methods 15

3.1 Subjects 15

3.2 Behavioural Apparatus 16

3.3 Sound Generation 17

3.4 Avoidance Equipment 17

3.5 Behavioural Conditioned Avoidance Procedure 18

3.6 Responses, Performance and Threshold 19

3.7 Retrograde Tract Tracing 20

3.8 Surgical Procedures 20

3.8.1 Pre-operative 20

3.8.2 Inferior Colliculus Lesion 21

3.8.3 Ear Block 22

3.8.4 Retrograde FG Iontophoretic Injections 23

3.8.5 Post-operative 24 
3.9 Histological Procedure 24

3.10 Statistical Analysis 25

4. Results 26

4.1 Normal Behaviour 26

4.2 Anatomical Classification 27

4.2.1 Ear Blocking $\quad 27$

4.2.2 Partial and Complete ICc Lesions 28

4.2.3 Retrograde FG Tracer Injections 29

4.3 Behavioural Effects of Lesions 30

5. Discussion 33

5.1 Behavioural Responses of rats with IC Lesions 33

5.2 Contralateral Pathway 36

5.3 Contribution of DNLL 39

5.4 Functional Recovery 40

$\begin{array}{ll}\text { 6. Conclusion } & 41\end{array}$

$\begin{array}{ll}\text { 7. References } & 87\end{array}$ 


\section{List of Abbreviations}

$\begin{array}{ll}\text { AC } & \text { auditory cortex } \\ \text { AVCN } & \text { anteroventral cochlear nucleus } \\ \text { BIC } & \text { brachium of the inferior colliculus } \\ \text { cochlear nucleus } \\ \text { DCN } & \text { dorsal cochlear nucleus } \\ \text { dorsal nucleus of the lateral lemniscus } \\ \text { FNLL } & \text { Fluoro-Gold } \\ \text { GABA } & \gamma \text { (gamma) -aminobutyric acid } \\ \text { IC } & \text { inferior colliculus } \\ \text { ICc } & \text { central nucleus of the inferior colliculus } \\ \text { ICd } & \text { dorsal cortex of the inferior colliculus } \\ \text { ICx } & \text { external cortex of the inferior colliculus } \\ \text { LNTB } & \text { lateral nucleus of the trapezoid body } \\ \text { LSO } & \text { lateral superior olivary nucleus } \\ \text { MAT } & \text { mean absolute threshold } \\ \text { MGB } & \text { medial geniculate body } \\ \text { MGBd } & \text { dorsal division of the medial geniculate body } \\ \text { MGBm } & \text { medial division of the medial geniculate body } \\ \text { MGBv } & \text { ventral division of the medial geniculate body } \\ \text { MNTB } & \text { medial nucleus of the trapezoid body } \\ \text { MSO } & \text { medial superior olivary nucleus } \\ \text { nLL } & \text { nuclei of the lateral lemniscus } \\ \text { PIN } & \text { posterior intralaminar nucleus } \\ \text { PVCN } & \text { posteroventral cochlear nucleus } \\ \text { SOC } & \text { superior olivary complex } \\ \text { VCN } & \text { ventral cochlear nucleus } \\ \text { VNLL } & \text { ventral nucleus of the lateral lemniscus } \\ \text { VNTB } & \text { ventral nucleus of the trapezoid body } \\ & \end{array}$




\section{List of Tables}

\section{Table}

1. Summary of lesions and thresholds for individual animals.

2. Mann-Whitney U pairwise comparisons of lesion groups.

3. Mann-Whitney U pairwise comparisons of thresholds in rats with partial or complete ICc lesions in ipsilateral and contralateral cases.

4. Mann-Whitney U pairwise comparisons of cases with intact or damaged DNLL in addition to complete ICc lesions

5. Descriptive statistics 


\section{List of Figures}

\section{Figure}

1 The ascending auditory pathway of the rat. 48

2. Central nucleus of inferior colliculus. 50

3. The superior olivary complex and the circuits of the principal nuclei. 52

4. Lateral lemniscal nuclei and their connections. 54

5. Summary of monaural pathways to the IC. 56

6. Summary of binaural pathways through the SOC and the nLL to the 58 inferior colliculus.

7. Schematic of the behavioural apparatus employed for the experiment. 60

8. Stimulus presentation. 62

9. Schematic illustration of the retrograde tract-tracing procedures used 64 for each experimental group.

10. Psychophysical curve of a normal animal (\#43). 66

11. Mean psychophysical curve based on performance of all normal 68 animals.

12. Efficacy of ear-blocking. $\quad 70$

13. Anatomical organization of the auditory midbrain. 72

14. Typical partial and complete ICc lesions.

15. The pattern of retrograde labeling in DNLL, VNLL and SOC for a 76 normal animal after a unilateral injection of FG into the left ICc

16. The pattern of retrograde labeling in the $\mathrm{CN}$ for a normal animal after 78 a unilateral injection of FG into the left ICc.

17. Retrograde FG labeling in an animal with a complete ICc lesion. $\quad 80$

18. Plot of the mean absolute thresholds for each animal by lesion group. 82

19. Plot of the mean absolute thresholds for animals with either ipsilateral 84 or contralateral ICc lesions with respect to completeness of their lesion.

20. Plot of the mean absolute thresholds for animals with or without

DNLL damage in addition to complete lesions of ICc. 


\section{BEHAVIOURAL CONSEQUENCES OF}

\section{UNILATERAL INFERIOR COLLICULUS LESIONS IN THE RAT}

\section{Introduction}

Although the inferior colliculus (IC) is one of the most thoroughly investigated structures in the central auditory system, there is very little information regarding its contribution to auditory behaviour. The purpose of this study is to provide fundamental data about the contribution of the IC to behavioural responses to acoustic stimuli. The introduction provides an overview of anatomical organization of the IC and its connectivity within the auditory pathway, and a brief review of those studies that address issues regarding behaviour and the IC. Finally it outlines the approach taken in this study to understand the role of the IC in hearing.

\subsection{The Inferior Colliculus (IC)}

The IC is a major component of the mammalian central auditory system. It is part of the midbrain tectum and receives both ascending and descending projections from the lower auditory brainstem and descending projections from auditory forebrain structures. Its large egg shape structure, measuring approximately $3.5 \mathrm{~mm}$ in length and $2 \mathrm{~mm}$ in width in Wistar and hooded rats (Faye-Lund \& Osen, 1985) alone makes it easily distinguishable from other midbrain structures. Retrograde tract tracing studies (Adams, 1979; Aitkin \& Phillips, 1984; Casseday, et al., 2002) have shown synaptic connections from almost all auditory nuclei in both ascending and descending paths, which converge on the IC. Taken together, its size and connectivity suggests the IC holds a prominent role in the auditory system. 


\section{- - - Insert Figure 1 about here - - -}

The IC displays a similar cytoarchitecture across different species such as the tree shrew (Casseday, et al., 1976), the North American opossum (Willard \& Martin, 1983), the bat (Zook, et al., 1985), the barn owl (Takahashi \& Konishi, 1988), the mouse (Willard \& Ryugo, 1983), the rat (Faye-Lund \& Osen, 1985), the cat (Oliver \& Morest, 1984; Winer, et al., 1998), various primate species (Fitzpatrick, 1975) and humans (Geniec \& Morest, 1971).

\section{- . - Insert Figure 2 about here - . -}

Although there is some variation in the size and appearance of the different subdivisions of the inferior colliculus, the central nucleus stands out in all mammals as the major component of auditory midbrain (Butler \& Hodos, 1996). Despite the numerous neuroanatomical, neuropharmacological and neurophysiological studies of the IC, there are very few $(<10)$ of the functional contribution of the IC to hearing (Masterton, et al., 1968; Strominger \& Oesterreich, 1970; Casseday \& Neff, 1975;

Jenkins \& Masterton, 1982; Kelly \& Kavanagh, 1994; Zrull \& Coleman, 1999).

\subsection{Subdivisions of the IC}

A century ago, Ramón y Cajal (1909) described a parcellation of the inferior colliculus by means of Golgi-impregnation of nerve cells and description of its cell types. 
The assortment of nuclear groups has since been modified and extended by different researchers. The simplest partition of the IC is into two parts: a central nucleus and pericentral nucleus. The most complex partition of the IC includes nine subdivisions (Morest \& Oliver, 1984; Huffman \& Henson, 1990). In the rat, Faye-Lund and Osen (1985) used Golgi impregnation as well as Nissl and myelin stains, and their subdivisions have been accepted as the standard for this species. They recognize three subdivisions: a central nucleus $(I C c)$ corresponding to the "noyeau de tubercle quadrijumeau posterieur" of Cajal; a dorsal cortex (ICd) (Cajal's "toit de tubercle quadrijumeau"); and an external cortex (ICx) (Cajal's "écorce externe"). Anatomically, the ICc is defined by its cells whose dendritic orientations form stacked sheets referred to as laminae (Casseday, et al., 2002). These laminae correspond to frequency specific physiological responses and are therefore often called iso-frequency laminae. When put together, both cortices create a shell or cap around ICc. Immunocytochemical probes employing calcium binding proteins have also been employed to distinguish the ICc from the cortices across several species (Oliver, 2005). For example, parvalbumin has a higher concentration in the ICc whereas calbindin and calretinin are shown to be higher in the ICd and ICx.

\subsection{Central Nucleus of the Inferior Colliculus (ICc)}

\subsubsection{Afferent Projections (Ascending)}

The ICc receives the principal afferent fibers of the ascending auditory system from more than ten lower auditory brainstem centers (Casseday, et al., 2002). This makes the ICc a major site of convergence of input from auditory structures involved in various aspects of sensory processing. More specifically, bilateral input to the ICc arises 
directly from all three divisions of the cochlear nucleus $(C N)$ viz., dorsal $(D C N)$, anteroventral $(A V C N)$, and posteroventral $(P V C N)$ cochlear nucleus (GonzalezHernandez, et al., 1996). The majority ( $\sim 81$ to $86 \%$ ) of these afferents are expressed as contralateral projections (Faye-Lund, 1986; Coleman \& Clerici, 1987). Other sources of input are, the superior olivary complex $(S O C)$ and the nuclei of the lateral lemniscus $(n L L)$.

\subsubsection{CN Projections to ICc}

Employing degeneration techniques, studies with cat (Warr, 1966; Osen, 1972), monkey (Strominger \& Strominger, 1971) and rat (Browner \& Webster, 1975) have conclusively demonstrated that both the ventral and dorsal portions of the cochlear nucleus project in a direct manner to the contralateral ICc. The neurons projecting to ICc from the VCN are thought to be primarily excitatory in function (Alibardi, 1998). Thus, the VCN is one of the main excitatory projections to the ICc (Helfert, et al., 1991). Stellate cells within the VCN are glutamatergic in nature (Romand \& Avan, 1997) and project directly to the contralateral ICc with collaterals to other auditory nuclei along the way (Kelly \& Caspary, 2005). In addition, these cells give rise to projections to the SOC and ventral nucleus of the lateral lemniscus (VNLL) (Cant, 2005; Schofield, 2005).

Glutamatergic fusiform cells in the DCN also send an excitatory direct projection to the ICc (Davis, 2002; Kelly \& Caspary, 2005). The ascending projections that arise from both portions of the cochlear nucleus overlap somewhat. They are represented in a topographic manner along iso-frequency laminae in the ICc (Osen, 1972; Adams, 1979; Oliver, 1984a). In this way, sound frequencies which are represented along the length of the cochlear partition, are mapped in a precise fashion onto various auditory nuclei 
including the ICc, and the projection of fibers ascending in the auditory pathway maintain this 'tonotopic' organization (Brunso-Bechtold, et al., 1981; Ryugo, et al., 1981; Zook \& Casseday, 1982; Oliver, 1984a). In this manner, cells in the low frequency region of the $\mathrm{CN}(V C N)$ project to dosolateral portion of the ICc, and the cells in the high frequency region of the $\mathrm{CN}(D C N)$ project to ventromedial portion of the ICc (Osen, 1972). Very few cells in the $\mathrm{CN}$ project to the ipsilateral ICc. These appear to be mainly from low frequency areas of the VCN (Nordeen, et al., 1983; Oliver, 1984a).

\subsubsection{SOC Projections to ICc}

The medial superior olivary nucleus $(M S O)$ and the lateral superior olivary nucleus $(L S O)$ are the two principal nuclei within the SOC. The SOC is considered to be the first site in the ascending pathway where binaural responses are observed, indicating that they play an important role in processing binaural cues (time and level disparities between the two ears) involved in sound localization (Roth, et al., 1978; Adams, 1979).

The MSO receives direct bilateral excitatory input from spherical bushy cells in the VCN. Additionally it also receives indirect inhibitory input from the contralateral VCN through the medial nucleus of the trapezoid body $(M N T B)$, or from the ipsilateral VCN through the lateral nucleus of the trapezoid body (LNTB) (Schofield, 2005). These binaural inputs make the MSO sensitive to small timing differences in the arrival of sound at the two ears, a factor that is important for the perception of spatial location of a sound source. In turn these neurons, which are also organized tonotopically, project to the ICc. The majority of the projections from the MSO to the ICc are ipsilateral (Coleman \& Clerici, 1987). Studies in which the uptake of labeled 2-deoxyglucose has been measured 
indicate that the MSO is most strongly stimulated by inputs from the contralateral side (Masterton \& Imig, 1984).

The LSO also receives direct excitation from the ipsilateral VCN. It also receives an inhibitory projection from the glycinergic neurons in the MNTB. The contralateral ventral nucleus of the trapezoid body $(V N T B)$ gives rise to inhibitory GABAergic input to the LSO as well. Finally, the ipsilateral LNTB provides inhibition from globular bushy cells in the VCN (Schofield, 2005).

The neurons in the LSO are sensitive to small intensity differences between the two ears. These binaural level differences provide cues for the location of sounds in space. Sounds located on one side of the head excite neurons in the ipsilateral LSO and inhibit neurons in the contralateral LSO. The LSO projects bilaterally to the ICc, with an excitatory contralateral projection and an inhibitory ipsilateral projection. Like the MSO, the LSO is tonotopically organized, but represents mainly high frequencies ( $\mathrm{Li} \&$ Kelly, 1992; Sally \& Kelly, 1992).

\section{- - - Insert Figure 3 about here - - -}

This crossing of projection in the auditory lower brainstem has led some to refer to it as an "acoustic chiasm" (Glendenning, et al., 1981), leading to a contralateral representation of auditory space that is similar to the way visual space is represented. More specifically auditory space may be divided into left and right fields and above the level of the SOC these fields are represented primarily in auditory structures including the ICc, on the opposite side of the brain. (Kitzes, et al., 1980; Glendenning, et al., 1981; 
Phillips \& Irvine, 1981). In other words, at the level of the ICc and above, the representation of auditory space is contralateral. No evidence has yet been found for a precise map of auditory space in the IC in mammals, although a map does exist in the barn owl in its homologue of the IC, the lateral dorsal mesencepalic nucleus (Knudsen \& Konishi, 1978; Takahashi \& Konishi, 1988). This midbrain nucleus in the barn owl represents space on the contralateral side.

\subsection{4 nLL Projections to ICc}

Two principal subdivisions exist in the nLL, the ventral nucleus of the lateral lemniscus $(V N L L)$ and the dorsal nucleus of the lateral lemniscus $(D N L L)$.

The VNLL receives input from the contralateral VCN as well as from the ipsilateral MNTB (Ortel \& Wickesberg, 2002; Schofield, 2005). The cells in the VNLL are principally excited by contralateral stimulation (Batra \& Fitzpatrick, 2002), and they appear to use GABA and glycine for neurotransmission, making the input from VNLL to ICc an inhibitory projection (Thompson, et al., 1985; Saint Marie \& Baker, 1990). Upon labeling with injection of retrograde tracers into the ICc, the VNLL appears to terminate heavily in the central nucleus of the inferior colliculus (Brunso-Bechtold, et al., 1981). This projection is ipsilateral in nature and is the most robust inhibitory source into the ICc (Helfert, et al., 1991). Unlike most auditory structures, the VNLL is not obviously arranged in a tonotopic fashion (Glendenning \& Hutson, 1998).

The DNLL receives input from both VCN as well as SOC. The SOC projections come from an ipsilateral MSO excitatory projection and from bilateral LSO projections, with an emphasis on contralateral excitation. The VNLL also projects ipsilaterally to the 
DNLL (Helfert \& Aschoff, 1997). Interestingly, the DNLL projects to the contralateral DNLL and ICc by means of the commissure of Probst (Ito, et al., 1996; van Adel, et al., 1999). The DNLL neurons are GABAergic and they project to both ipsilateral and contralateral ICc, the contralateral projection being stronger (Helfert \& Aschoff, 1997). The nucleus does appear to have a concentric tonotopic organization with high frequencies represented along the outer rind and low frequencies represented in the core (Saint Marie, et al., 1999).

\section{- - - Insert Figure 4 about here - - -}

\subsubsection{Monaural and Binaural Pathways}

Ascending afferents to the ICc can also be distinguished on the basis of whether they are monaural or binaural in nature (Helfert, et al., 1991; Helfert \& Aschoff, 1997; Casseday, et al., 2002). Monaural and binaural pathways likely serve different functions suggested by the physiologic properties of the neurons that give rise to them (Schofield, 2005).

The monaural pathway consists of direct projections from the contralateral and ipsilateral DCN and VCN. There is also an indirect projection to the ICc via multipolar cells in the VCN to the VNLL. The monaural projection pathways to the ICc by either direct or indirect routes are predominantly contralateral. The projections consist of both excitatory and inhibitory synapses. It has been suggested that monaural pathways are important for timing of responses, analysis of temporal features of sound (Casseday, et al., 2002) and 'pattern recognition' (Ortel \& Wickesberg, 2002). 


\section{- - - Insert Figure 5 about here - - -}

The binaural pathway originates at the level of the SOC with input of spherical bushy and globular bushy cells from the VCN bilaterally. The key nuclei in this path are the MSO, the LSO and the DNLL. The crossed and uncrossed projections consist of both excitatory and inhibitory synapses. The binaural pathways have been implicated in the integration of interaural differences for sound source localization (Casseday, et al., 2002; Schofield, 2005).

\section{- - - Insert Figure 6 about here - - -}

\subsubsection{Efferent Projections (Ascending) from ICc}

The ICc projects largely to the ipsilateral ventral $(M G B v)$ division of the medial geniculate body $(M G B)($ Oliver, 1984b; Morest \& Winer, 1986; Frisina, et al., 1997; Malmierca, et al., 1997; Wenstrup, 2005), with no evidence of a contralateral projection (Frisina, et al., 1997; Malmierca, et al., 1997). The MGBv preserves the systematic representation of characteristic frequencies inherited from the ICc and sends projections to the auditory cortex (Imig \& Morel, 1984). Physiological studies show preservation of a cochleotopic (i.e., tonotopic) representation all the way to the primary auditory cortex with responses determined primarily by stimulation of the contralateral ear (Kelly \& Sally, 1988). 


\subsubsection{Neuronal Organization of the ICc}

The ICc is defined by the presence of sheets or laminae, which are composed of

small, densely packed neurons with flattened dendritic arbors. These are usually referred to as 'fibrodendritic laminae' (Morest, 1964). The sheets run in a ventrolateral to dorsomedial plane, and are stacked in parallel giving rise to the ICc's laminated structure (Oliver \& Morest, 1984; Faye-Lund \& Osen, 1985). The cells which make up the fibrodendritic laminae in rat ICc have been referred to as flat neurons (Malmierca, et al, 1993). This cell type matches the conventional definition of disk-shaped neurons previously described in the cat (Oliver \& Morest, 1984). The dendritic arbors of the flat cells run in parallel and form laminae approximately $40-70 \mu \mathrm{m}$ thick (Faye-Lund \& Osen, 1985). Neurons referred to as less flat (Malmierca, et al., 1993), or stellate in the cat (Oliver \& Morest, 1984), lie next to the flat neurons in interlaminar regions between the laminae. Their arbours are approximately twice the size of the flat sheets. The laminae are thought to be the morphological substrate for the tonotopic organization. Low characteristic frequencies are represented in the dorsolateral laminae and high characteristic frequencies are represented in the ventromedial ones (Hind, et al., 1963; Morest, 1964; Clopton \& Winfield, 1973; Rockel \& Jones, 1973a, 1973b; Fitzpatrick, 1975; Flammino \& Clopton, 1975; Semple \& Aitkin, 1979; Morest \& Oliver, 1984; Oliver \& Morest, 1984; Huang \& Fex, 1986; Kelly, et al., 1991; Malmierca, et al., 1993). These laminae match the tonotopic organization found in the nuclei of the SOC as well as cells in the $\mathrm{CN}$ that send their projection to the ICc. Early electrophysiological studies (Rose, et al., 1966; Clopton \& Winfield, 1973; Merzenich \& Reid, 1974) presumed that the ICc tonotopicity from low to high frequency was continuous, however 
more recent investigations employing smaller and more precise electrode penetration of the ICc in both the cat (Schreiner \& Langner, 1997), and the rat (Malmierca, et al., 2008) reveal a stepwise or discontinuous progression. Understanding this coding is important for clinical application of a midbrain auditory implant currently under development (Lim, et al., 2007) for patients who suffer from ailments such as the genetic disorder neurobribromatosis type 2. These patients suffer sensorineural hearing loss derived from Schwann cell tumors found on the auditory $\left(8^{\text {th }}\right.$ cranial $)$ nerve, and therefore these patients are not candidates for the popular and highly successful cochlear implant to restore speech perception.

Anatomical results taken from Golgi impregnation (Malmierca, et al., 1993) reveal a relatively homogeneous organization in the ICc. However, physiological studies indicate that these cells are involved in more complex roles than tonotopicity alone. Differences in ionic currents make some neurons in the ICc more likely to integrate information relating to timing and intensity whereas other neurons act as simple relays (Sivaramakrishnan \& Oliver, 2001). Some cells are excited by binaural stimulation whereas others are exclusively excited by monaural stimulation. Binaural cells sensitive to timing are segregated from those that are sensitive to binaural level differences (Roth, et al., 1978; Adams, 1979). Therefore, anatomy alone does not fully reveal the functional roles for which neurons in the ICc are specialized. 


\subsection{Behavioural Studies}

Anatomical studies of patterns of projections to the IC suggest that the representation of auditory information in the IC may be largely contralateral. The majority of the projections from all three divisions of the $\mathrm{CN}$ to the ICc are contralateral in the rat (Coleman \& Clerici, 1987). In addition, the excitatory projections from the LSO as well as the projections from the DNLL to the ICc are predominantly contralateral (Coleman \& Clerici, 1987). Similar anatomical findings have been obtained in the cat (Adams, 1979; Brunso-Bechtold, et al., 1981). Furthermore, Masterton and Imig (1984) have shown that the MSO is most strongly stimulated by inputs from the contralateral side.

Neurophysiological research has demonstrated that the ICc has cells which are sensitive to binaural time and/or level differences resulting in a contralateral representation of space (Hind, et al., 1963). In the rat, the majority of neurons are sensitive to binaural input and are driven by contralateral stimulation. Kelly and Kavanagh (1994) point out that numerous physiological studies have supported the idea of contralateral representation. Monaural stimulation of the contralateral ear also elicits responses in the contralateral ICc. Taken together, evidence from anatomical and physiological studies point to the possibility that auditory information is represented contralaterally in the IC. It is then of interest to examine this possibility by determining the behavioural consequences of unilateral lesions of the ICc ipsilateral and contralateral to the ear activated by a sound. However, very little information is available about the consequences of unilateral ICc lesions. 
At the highest level of the central auditory pathway, unilateral auditory cortex lesions have been shown to result in severe behavioural deficits in sound localization contralateral to the site of the lesion in various mammalian species (Neff \& Casseday, 1977; Jenkins \& Masterton, 1982; Thompson \& Cortez, 1983; Jenkins \& Merzenich, 1984; Kelly, et al., 1986; Kavanagh \& Kelly, 1987). Bilateral lesions of the auditory cortex in the rat, however, do not lead to severe impairments in sound localization and normal rats perform poorly in lateral field sound localization (Kelly \& Glazier, 1978; Kelly, 1980; Kelly \& Kavanagh, 1986). These results suggest that in the rat, the auditory cortex may be unnecessary for auditory spatial discrimination. Bilateral cortical lesions in the rat have been shown to cause a diminished behavioural performance or impairment in temporal processing (Ison, et al., 1991; Kelly, et al., 1996; Syka, et al., 2002; Bowen, et al., 2003), however it has been shown that over a prolonged period of time, there is functional recovery after cortical damage (Burke \& Kelly, 2009; Clarkson, et al., 2010). Unilateral lesions lower in the brainstem within the SOC produce bilateral deficits in sound localization (Moore, et al., 1974; Casseday \& Neff, 1975; Jenkins \& Masterton, 1982; Kavanagh \& Kelly, 1992), whereas unilateral lesions of the ICc produce predominantly contralateral deficits in sound localization in the ferret (Kelly \& Kavanagh, 1994). There have been no published reports on the effects of unilateral lesions of the ICc on aspects of hearing other than sound localization. 


\section{Purpose}

Most of the research on the inferior colliculus has dealt with neurophysiology and neuroanatomy with little attention given to the role of the inferior colliculus in behaviour and auditory perception. However, predictions based on anatomical and physiological data alone are often inadequate for fully understanding auditory ability of awake and behaving animals. The purpose of this study was to examine the effects of unilateral lesions of the inferior colliculus in the rat, and to relate the consequences of those lesions to what is known about the anatomical organization and physiological properties of this major auditory midbrain nucleus. The hypothesis, based largely on anatomical and physiological studies is that lesions of the inferior colliculus that destroy the contralateral ascending projection pathways would have a more profound effect on auditory sensitivity than equivalent lesions of the ipsilateral projection pathways. 


\section{Materials and Methods}

\subsection{Subjects}

34 male Wistar rats (Rattus norvegicus) approximately 300-350 grams upon arrival from Charles River Laboratories (St. Constant, Québec, Canada) were used in this study. Animals were single housed in a temperature and humidity controlled setting in the vivarium of the Life Sciences Research Building at Carleton University.

The subjects were maintained on a 12-hour light/dark cycle. All studies were conducted during the light phase of the cycle. All animals were provided with Purina rat chow ad libitum, and water was given ad libitum except during experimental periods. Animal cages were enriched with the provision of a straight or elbow joint Poly Vinyl Chloride plumbing tube (approx. $20 \times 15 \mathrm{~cm}$ ) and paper nesting material.

Behaviour was assessed in normal animals $(n=7)$ and animals with unilateral lesions of the IC $(n=21)$. All lesions were made in rats that had one ear blocked to produce a profound unilateral hearing loss. The IC lesions were made either ipsilateral ( $n$ $=5$ ) or contralateral $(n=16)$ (on the same, or opposite side) to the unblocked ear.

Therefore, comparisons could be made between groups to determine the effects of damaging the ipsilateral or contralateral projections pathways to the inferior colliculus.

Twenty-four hours prior to behavioural training all animals were deprived of water, which only became available during the training/testing period. Body weights were carefully monitored daily to ensure that the rats maintain greater than $95 \%$ of their original weight for optimal health. Unblocked ears were inspected using a Welch Allyn Otoscope to rule out infection or obstruction of the middle or outer ears respectively. 
All procedures of this study were carried out following Protocol PO9-9, which has been approved by the Carleton University Animal Care Committee in accordance with the guidelines of the Canadian Council on Animal Care.

\subsection{Behavioural Apparatus:}

Rats were tested in a small stainless steel metal mesh cage $30 \times 20 \times 20 \mathrm{~cm}$, suspended inside a large, single-wall sound attenuated chamber, internal dimensions 2.09 x $1.77 \times 2.01 \mathrm{~m}$ (Eckel Industries, Belleville, ON). The wire mesh of the cage was designed to be sound transparent to avoid blocking sound delivery. For total acoustic isolation, the sound attenuated chamber was located in a room on its own and located adjacent the room where the experimenter observed the animal through live video feed and manipulated electronic test equipment. Inside the chamber, the test cage was fitted with a reward spout from which the rats consumed their daily intake of water. The spout protruded $4 \mathrm{~cm}$ above the $1 \times 1 \mathrm{~cm}$ screen mesh at a height where the animals could make contact with it comfortably. $2 \mathrm{~cm}$ behind the spout, a metal plate $(13 \times 8 \mathrm{~cm})$ provided a contact circuitry. Contact between the plate and the spout caused water to flow to the spout. Delivery of distilled water to the spout came through polyethylene tubing attached to a Yale Apparatus syringe pump (model YA-12). The pump was connected to a computer that automatically registered the time the rats were in contact with the spout. Data were collected on a computer connected to the apparatus by a TDT digital I/O interface (Tucker-Davis Technologies, Alachua, FL). Flow rate through the water delivery system averaged between $0.8-1.2 \mathrm{ml} /$ minute and a typical daily trial run lasted approximately thirty minutes. 


\subsection{Sound Generation:}

A loudspeaker was placed $70 \mathrm{~cm}$ in from of the spout so that animals would face the speaker while consuming water. The speaker was comprised of a midrange and a tweeter speaker (KEF models SP1032 and T27, respectively; KEF Electronics Ltd., Maidstone, Kent, UK). Digital broadband white noise was generated and controlled by a computer attached to a TDT System 3 Real Time Processor (model RP-2), and finally passed through a power amplifier (Aiwa P30). To be certain that sound pressure levels were consistent, calibrations were made frequently with a Brüel \&Kjær Sound Level Meter with a half-inch condenser microphone (model 3133; Brüel \& Kjær Instruments, Nærum, Denmark). The condenser microphone was placed in a location corresponding to the position of an animal's head in front of the water spout. Humidity was controlled with the assistance of a dehumidifier in the behavioural chamber when testing was not in progress.

\subsection{Avoidance Equipment:}

To create a conditioned avoidance, mild electrical shocks were delivered to the animals through the lick spout when the subject continued contact during a sound stimulus presentation. The animal's withdrawal responses to acoustic stimuli were recorded by a computer with custom designed software (Avalon DSP, Ottawa, ON) indicating if a rat was able to recognize the presentation of the sound stimulus. The shock elicited was avoidable provided the animal could detect the presence of the sound stimulus. The current source for delivering shocks (Lafayette model A-615 AR; Lafayette Instruments Corp., Lafayette, Indiana, USA) was gated by a double-pole, 
double-throw relay outside the sound-attenuated chamber. The current level was adjusted for individual animals to the lowest level that produced a reliable avoidance response. After the delivery of a shock, two lights flashed to indicate the termination of a trial. The lights were located on each side of the test apparatus at a distance of 4 centimetres. The flash acted as a safe signal cue to that the auditory stimulus has passed and that the animal could return to the spout without fear of receiving a shock.

\section{- - - Insert Figure 7 about here - - -}

\subsection{Behavioural Conditioned Avoidance Procedure:}

Behaviour in this study was assessed post-op, comparing between groups. Animals had a two week period to recover from surgery before training commenced. Animals were trained using a conditioned-avoidance procedure described by Heffner \& Heffner (1995). This procedure was used to determine auditory thresholds by reducing the intensity of the sound stimulus in successive presentations until an animal could no longer respond to the stimulus above the level expected by chance (Heffner \& Heffner, 1995).

Training commenced 24 hours after the initiation of water deprivation. Thirsty animals quickly learned to consume water from the spout located in the test cage. The animals consumed their daily intake according to their weight $\sim 40 \mathrm{ml} / \mathrm{kg} /$ day with typical training sessions lasting approximately 45 minutes/animal/day. 


\subsection{Responses, Performance and Threshold:}

After three days of learning how to drink from the spout, animals were introduced to sound stimuli considered to be well above their threshold. The detectable stimulus was then progressively reduced until performance levels dropped to chance.

The custom software (Avalon DSP, Ottawa, ON) presented successive sound stimuli at random intervals to avoid temporal conditioning. The animals soon learned to associate a change in sound with a shock and broke contact with the spout whenever they detected the stimulus to avoid the mild shock.

Cessation of licking during stimulus presentation was considered a "hit" response. Cessation of licking during periods with no stimulus is considered was "false alarm" response. We used the formula for calculating performance described originally by Heffner and Heffner (1995). The equation is as follows:

\section{Performance $=$ Hit Rate $-($ Hit Rate $x$ False Alarm Rate $)$}

The calculation yields scores from 0 to 1.0 indicating respectively as a complete failure to discriminate and perfect discrimination. These values were then plotted and the 0.5 performance level was used to define thresholds by simple linear interpolation. 


\subsection{Retrograde Tract Tracing:}

Retrograde transport was carried out using Fluoro-Gold ( $F G$, 2-hydroxy-4,4'diamidinostilbene, $204 M_{\mathrm{W}}$, Fluorochrome, Inc., USA) in each of animal used to study the behavioural effect of making an IC lesion $(N=28)$. FG allowed us to determine the effects of lesions on structures not directly damaged by the removal of ICc. The use of fluorescent axonal tracers is popular for a number of reasons including high sensitivity, simplicity and compatibility with other techniques. FG is a fluorescent stilbene derivative (2-hydroxy-4,4'-diamidino-trans-stilbene), which consists of two benzene rings connect to a vinyl linkage. The alternating single and double bond configuration of the FG molecule results in a resonant structure where $\pi$-orbital clouds contain the outer most electrons. Exposure to ultraviolet (UV) light excites these outer electrons to higher energy levels, and when returned to a lower energy level, light is emitted which can be visualized by means of fluorescence microscopy.

FG is commonly used to demonstrate long-term retrograde labeling without fading or degradation. It is easily released by iontophoresis, and more importantly it is not taken up by undamaged fibers-of-passage.

\subsection{Surgical Procedures:}

\subsubsection{Pre-operative :}

Isoflurane gas (Abbott Laboratories, North Chicago, IL) was employed for induction of anesthesia during all surgical procedures. An intramuscular injection of ketamine hydrochloride, $30 \mathrm{mg} / \mathrm{kg}$ (Ketaset, Wyeth, Guelph, ON) was used in conjunction with the isoflurane gas to induce an areflexive state. In preparation for surgery an 
animal's head was shaved and sterilized with Germi-Stat (Germinphene Corporation, Branford, ON). The animal's head was firmly held in place with a nose clamp. Teargel (Novartis Pharmaceuticals, Mississauga, ON) was applied to the animal's eyes to prevent them from drying and to protect them from irritants. Atropine Sulphate, $0.5 \mathrm{mg} / \mathrm{ml}$ (Bimeda-MTC, Cambridge, ON) was also be administered to the animal sub-cutaneously to prevent bronchial congestion during anaesthesia.

\subsubsection{Inferior Colliculus Lesion:}

A midline incision was made in the scalp and the skull was exposed. The temporal muscle was retracted and a craniotomy was performed on the side of the surgical lesion with use of an Olympus SZ40 surgical microscope (Olympus, Center Valley, PA, USA). The craniotomy extended ventral-laterally along the zygomatic arch. The bone was thinned with a surgical drill and carefully removed with fine curved forceps to prevent damage to the underlying vascular sinus. The dura was then cut with a scalpel and retracted. Aspiration of only the most caudal end of neocortex was performed to reveal the inferior colliculus, which was visualized through the dissecting microscope. The membrane covering the IC was cut and the neural tissue was removed by aspiration with a fine tipped pipette. The craniotomy was covered with Gelfoam (Pharmacia \& Upjohn, Bridgewater, New Jersey, USA). Muscular bleeding was controlled with use of a high frequency dessicator and bipolar forceps (Aaron 940, Bovie Medical Corp., Clearwater, FL, USA). Vicryl sutures (Johnson and Johnson, Markham, $\mathrm{ON}$ ) were used to fasten the fascia over the craniotomy and non-absorbable Ethilon sutures (Johnson and Johnson, Markham, ON) were used to close the surgical incision. 


\subsubsection{Ear Block:}

An ear blocking procedure was designed and used to produce a profound conductive hearing loss. The purpose of the ear block was to eliminate hearing in one ear so that the effect of ipsilateral and contralateral IC lesions could be ascertained. The ear block procedure produced unilateral deafness without complications associated with surgical destruction of the inner ear (i.e. cochlear and/or vestibular damage).

A midline incision was made and the fascia was retracted. On the side where the ear block was made, a fiber-optic light (MI-150 Fiber-Lite, Dolan Jenner Industries, Boxborough, MA, USA) provided a bright source of illumination of the middle ear. A pair of very fine forceps were then used to make a tympanectomy and ossiculectomy of the malleus and incus; care was given to leave the stapes in place as it provides vasculature for the inner ear through the stapedial artery and holds perilymph within the cochlea. The auditory meatus was carefully dissected and two pairs of size 0.0 surgical silk braid suture (Ethilcon, Johnson \& Johnson, Markham, ON) were passed around the meatus. A vulcanizing silicone compound (Otoform Ak, Dreve Brand, Hamburg, Germany) was mixed and injected into the bulla to freeze the stapes and fill the meatus. When the compound hardened the silk threads were used to ligate the meatus and hold the compound firmly within the middle and external ear. Ethilon sutures were used to close the surgical incision site. 


\subsubsection{Retrograde FG Iontophoretic Injections:}

A midline incision was made in the scalp, the facia was retracted laterally, and a craniotomy was performed over inferior colliculus employing the same approach as the IC lesion. After visualizing the un-lesioned IC, using a Kopf stereotaxic apparatus (David Kopf Instruments, Tujunga, California, USA) injections of 2\% FG were made in the central nucleus of the inferior colliculus. The injection pipette (diameter of 15-20 $\mu \mathrm{m})$ was lowered into all injection sites at a vertical angle of 26 degrees relative to the sagittal plane. Three injections were made: a ventromedial injection where the pipette was lowered $1.80 \mathrm{~mm}$, a ventrolateral injection where the pipette was lowered $1.00 \mathrm{~mm}$, and a dorsolateral injection of $1.00 \mathrm{~mm}$. All injections were made by iontophoresis, passing an alternating ( 8.0 seconds on/ 8.0 seconds off) positive $8.0 \mu \mathrm{A} \mathrm{DC}$ current through the glass pipette for a period of 10 minutes. After each injection, the pipette was left in place for 5 minutes without current to prevent any type of leakage of the tracer along the injection tract. The craniotomy was covered with Gelfoam. Vicryl sutures were used to fasten the fascia over the craniotomy and non-absorbable Ethilon sutures were used to close the surgical incision. Animals were given at least 7 days after their injections to allow for sufficient transport of the FG. They were then euthanized, their brains were removed and the tissue was processed in histology.

\section{- - - Insert Figure 9 about here - - -}




\subsubsection{Post-operative:}

All surgical procedures concluded with the injection of Metacam $(5.0 \mathrm{mg} / \mathrm{kg}) \mathrm{a}$ non-steroidal anti-inflammatory drug (Boehringer Ingelheim, Burlington, ON). $10.0 \mathrm{ml}$ of Plasma-Lyte A (Baxter Corporation, Mississauga, ON) was also administered to replenish electrolytes. Crushed rat chow was combined with water to create a food paste for the animals to consume following surgery. Animals were given Metacam, PlasmaLyte A and food paste for 3 days following surgery. Their body weights were carefully monitored for five days after surgery. Ethilon sutures were removed 7 days postoperatively under isoflurane.

\subsection{Histological procedure:}

Following completion of behavioural testing and retrograde transport of FG, rats were deeply anesthetized with sodium pentobarbital $(50 \mathrm{mg} / \mathrm{kg}$ ) intraperitoneally (IP) and perfused transcardially with heparinized saline ( 20 units $/ \mathrm{ml}$ in $0.9 \% \mathrm{NaCl})$ followed by $4 \%$ paraformaldehyde (PFA) in $0.1 \mathrm{M}$ phosphate buffer solution (PBS) $(\mathrm{pH}=7.4)$ in preparation for histology. Brains were removed and placed in a 4\% PFA in $0.1 \mathrm{M}$ PBS solution. The following day, the cerebellum and cortex was carefully dissected from the brainstem. Post-fixation, the brainstems were transferred to $25 \%$ sucrose and cut serially at 40 microns in the frontal plane on a cryostat. Sections were then mounted on gelatinized slides and air dried overnight. One series was stained with cresyl violet; the other series for FG required no further processing. Slides from both series were coverslipped with Permount. 
A Zeiss Axioplan light microscope (Carl Zeiss, Jena, Germany) with a digital camera attachment was used for photography of the inferior colliculus lesions. Digital photographs were taken so the extent of the lesions could be accurately determined.

\subsection{Statistical Analysis}

Statistical analysis of behavioural results was performed in SPSS. Threshold data was interpolated as described above from psychophysical curves describing performance at different levels of stimulus intensity. Data were then analyzed with the non-parametric Kruskall- Wallis ANOVA and Mann-Whitney $U$ test. 


\section{Results}

The data presented here are based on behavioural responses from 34 rats. 6 rats were used to show the efficacy of ear blocking. For the analyses of the behavioural auditory sensitivity thresholds of each rat, groups were created based on the type of surgical manipulation the rat received. The groups were comprised of normal rats with no surgical intervention $(n=7)$, rats with ipsilateral IC lesions $(n=5)$, and rats with contralateral IC lesions $(n=16)$. Ipsilateral and contralateral in this context refer to the side of the IC lesion relative to the unblocked ear. Each animal was trained and tested using the same conditioned avoidance behavioural approach with the goal of obtaining a psychophysical curve of their respective performance levels. Following behaviour each animals intact IC was injected with FG to trace the anatomical projections to this structure.

\subsection{Normal Behaviour}

The conditioned avoidance procedure assessed each animal's ability to discriminate $200 \mathrm{~ms}$ broadband white noise bursts at various intensities (sound pressure levels). Beginning from a high SPL, $90 \mathrm{~dB}$, then using 10 decibel decrements in the method of descending limits to $0 \mathrm{~dB}$, responses to sound stimuli were recorded by our computer program to calculate a mean performance at each intensity presented. These data were averaged in SPSS and psychophysical curves were plotted.

Illustrated in Figure 10 is the psychophysical curve of mean performance for one normal individual (\#43). Superimposed is the 0.5 criterion level of performance for 
determing threshold. By means of interpolation, this animal had a mean performance threshold of $18.75 \mathrm{~dB}$.

\section{- - - Insert Figure 10 about here - - -}

The procedure for calculating thresholds from psychophysical curves was repeated for each normal animal. The mean group psychophysical curves were plotted in SPSS, as illustrated in Figure 11. This figure shows the mean performance threshold \pm SD for all animals in the normal group. The threshold for normal rats based on their mean psychophysical curve was $20.97 \pm 9.72 \mathrm{~dB}$ SPL.

\section{- - - Insert Figure 11 about here - - -}

\subsection{Anatomical Classification}

\subsubsection{Ear Blocking}

Part of evaluating the behavioural limits of performance for animals with unilateral IC lesions was to be sure we could deafen animals sufficiently in one ear. Therefore, 6 animals were used to show the effectiveness the ear blocking procedure in producing a conductive hearing loss. Both ears were blocked in 3 animals, whereas 3 other animals received only a midline incision (sham). Following a two-week recovery period, the untrained animals' response to sound was evaluated. A blind observer scored their startle responses to noise bursts of 0 and $90 \mathrm{~dB}$. A startle was defined as the animal 
either flinching or freezing in response to the noise presented. The results showed that the ear block procedure was effective. Animals whose ears were blocked bilaterally showed a startle response to the more intense sound only $3.5 \%$ of the time $(6 / 170$ trials). This result showed the procedure produced a profound hearing loss in the blocked ear without causing damage to the cochlear apparatus.

\section{- - - Insert Figure 12 about here - - -}

\subsubsection{Partial and Complete ICc lesions}

A unilateral lesion of the inferior colliculus together with a unilateral ear block and was performed on 21 subjects. Animals were given a recovery period of 2 weeks before the initiation of training. After the animals reached stable performance levels in response to sounds, their thresholds were obtained from psychophysical curves as previously described. Once thresholds had been determined, the animals were again prepared for surgery and their intact IC was injected with FG for retrograde tract tracing. To delineate the extent of the lesions performed on each animal, brains were cut in the frontal plane for Nissl and FG. An illustration of the anatomical regions of interest can be seen in Figure 13. The IC lesions were classified as either partial or complete. Figure 14 illustrates both a partial and complete lesion. A partial lesion was defined as one that did not include the entire ICc. A complete lesion was one that included all of ICc. The extent and placement of the ICc lesions were compared with their behavioural results to determine the effect of the lesions on absolute thresholds. 


\section{- - - Insert Figure 13 about here - - -}

\section{- - - Insert Figure 14 about here - - -}

\subsubsection{Retrograde FG Tracer Injections}

Unilateral injections of FG into the ICc of normal animals allowed us to see the normal pattern of projections in the adult rat. The pattern of FG labeling is presented in Figures 15 and 16 and described below. After making 3 large iontophoretic injections of FG into the ICc, numerous positively labeled nerve cells were found in the ipsilateral and contralateral dorsal nucleus of the lateral lemniscus (DNLL). Many labeled neurons were observed in ventral nucleus of the lateral lemniscus (VNLL) ipsilateral to the ICc injection, whereas none were seen on the contralateral side. In the ipsilateral SOC heavy labeling was seen in each subdivision. However, in the contralateral SOC only the LSO was heavily labeled.

\section{- - - Insert Figure 15 about here - - -}

All three levels of the $\mathrm{CN}$, the anteroventral cochlear nucleus (AVCN), the posteroventral cochlear nucleus (PVCN) and the dorsal cochlear nucleus (DCN) contained the most numerous FG labeled neurons contralateral to the injection site. In contrast, only a few labeled cells were seen in the ipsilateral CN. 


\section{- - - Insert Figure 16 about here - - -}

No abberent projections were seen in any of the animals with IC lesions. Identical pattern of FG-labeling was seen in all lower auditory brainstem structures in each of these cases.

The retrograde transport of FG was also useful in assisting us to delineate the extent of lesions. We could determine whether or not the lesions extended ventrally into the DNLL by examining the retrograde labeling with FG injected to the opposite ICc. Figure 17 shows a reconstruction of an entire section of tissue under fluorescent microscopy for a rat with a complete lesion of ICc that left the DNLL intact. The patterns of contralateral labeling was compromised in cases with damage to DNLL as well as ICc. A summary of behavioural thresholds and the extent of the lesions in each animals is given in Table 1.

\section{- - - Insert Figure 17 about here - - -}

\subsection{Behavioural Effects of Lesions}

Each animal was tested using the same conditioned avoidance behavioural method for determining absolute threshold. The groups were compared based on their respective absolute thresholds. Thresholds for normal animals and animals with either ipsilateral or contralateral ICc lesions are shown in Figure 18. The data reveal individual thresholds as well as the mean of each group \pm SD. It can be seen that the lesion groups 
substantially differ from one another. The difference in the mean thresholds of each group is significant, as indicated by the non-parametric Kruskal-Wallis ANOVA, $\chi_{(2, N=28)}^{2}$ $=16.83, p=0.00$. We used pairwise comparisons among the three groups to determine the differences of each group from one another. All data were rank ordered by mean intensity threshold for pairwise comparisons. Each comparison was made using a twotailed Mann-Whitney $U$; the summary of these results is given in Table 2. The results show that animals with ipsilateral lesions do not differ significantly from normal animals with respect to their thresholds (Mann-Whitney test, $Z=.893, p=.372$ ). Animals with contralateral lesions, on the other hand, were significantly different from both normal animals (Mann-Whitney test, $Z=3.055, p=.001$ ) and animals with ipsilateral lesions (Mann-Whitney test, $Z=3.408, p=.002$ ).

\section{- - - Insert Figure 18 about here - - -}

Because of the large variation in scores for animals in the contralateral lesion group (seen in Figure 18), we surmised that the anatomical extent of lesion was the basis for this difference. Therefore, to test this difference, comparisons were made separately for animals with partial or complete lesions of the central nucleus of inferior colliculus. The data are shown in Figure 19, which gives both individual thresholds and mean thresholds of each group $\pm \mathrm{SD}$. For reference, a dashed is line superimposed to indicate the mean threshold for the normal group. Mann-Whitney $U$ tests show no difference between animals with partial and complete lesions of the ipsilateral ICc (Mann-Whitney test, $Z=1.732, p=.083$ ). On the other hand, there was a significant difference between 
animals with partial and complete lesions of the contralateral ICc (Mann-Whitney test, $Z$ $=3.115, p=.002$ ). A summary of these results is shown in Table 4 .

\section{- - - Insert Figure 19 about here - - -}

The retrograde iontophoretic injections of FG allowed us verify whether complete lesions of the central nucleus of the inferior colliculus encroached on another auditory nucleus, the dorsal nucleus of the lateral lemniscus. To determine whether damage to DNLL contributes to deficits to auditory sensitivity produced by ICc lesions, we made comparisons of threshold for animals with or without additional damage DNLL.

Comparisons were made for rats with lesions either ipsilateral or contralateral ICc. The data were plotted as in Figure 19, showing both individual thresholds and mean thresholds for each group. The mean threshold for the normal group is also shown as a dashed line across the plot. For animals with ipsilateral lesions, we found no difference between rats with and without damage to DNLL (Mann-Whitney test, $Z=1.225, p=$ .221). For those with contralateral lesions of ICc, however, thresholds were significantly higher with DNLL damage (Mann-Whitney test, $Z=2.449, p=.014$ ). Table 4 provides a summary of these comparisons.

\section{- - - Insert Figure 20 about here - - -}

A summary of the descriptive statistics for each of the various groups of animals is given in Table 5 . 


\section{Discussion}

This study provides behavioural data on the effects of unilateral IC lesions on the sensitivity of rats to sound as indicated by their absolute thresholds for detecting a 200 ms broadband noise burst. The results show differences in the effects of lesions that totally destroyed the inferior colliculus on the side ipsilateral or contralateral to the normally functioning ear in animals that had been deafened unilaterally by a conductive ear block. The data agree with anatomical and physiological reports that the inferior colliculus is an important midbrain structure for basic auditory functions and show the overriding importance of the contralateral projection pathways for hearing and the maintenance of normal sensitivity to sounds.

\subsection{Behavioural responses of rats with IC lesions}

The results of this study are consistent with the idea that the inferior colliculus is necessary for maintenance of the most fundamental auditory function, i.e. absolute sensitivity to sound as determined by learned behavioural responses to a broadband noise. Thresholds for detecting the presence of noise were greatly elevated by lesions that completely destroyed the contralateral IC. Following such lesions, sensitivity was decreased to an extent that precluded further behavioural tests of more complex auditory behaviours such as frequency discrimination, level discrimination, gap detection or other forms of temporal processing.

The behavioural results reinforce anatomical data that indicate the IC is a 'central hub' or 'nexus' for processing converging auditory input from lower brainstem structures (Casseday, et al., 2002; Malmierca \& Merchán, 2004; Oliver, 2005). The central nucleus 
of the inferior colliculus receives input from several lower auditory brainstem centers, including projections from the cochlear nuclear complex, superior olivary complex and nuclei of the lateral lemniscus. These projections converge on the central nucleus of the inferior colliculus, as demonstrated by retrograde axonal transport of tracers injected into the IC as well as anterograde tract tracing using various transport methods (Adams, 1979; Aitkin \& Phillips, 1984; Casseday, et al., 2002; Cant, 2005; Kelly, et al., 2009).

Anatomical results from the present study confirm that these projections all converge on the central nucleus of the inferior colliculus (Figures 15 and 16).

Complete lesions of the inferior colliculus result in a $40-45 \mathrm{~dB}$ elevation in the absolute threshold for detecting a noise stimulus. This result indicates that the inferior colliculus is essential for detecting the presence of acoustic signals in the environment and for establishing a basic learned response (shock avoidance) to sounds. An elevation of threshold of $45 \mathrm{~dB}$ represents a marked impairment in hearing. Thresholds are shifted from $20 \mathrm{~dB}$ in normal animals to around $65 \mathrm{~dB}$ in animals with complete destruction of the contralateral inferior colliculus. In humans, this deficit would be considered clinically significant and would be expected to disrupt the ability to process important environmental and social communication signals including speech sounds. Complete destruction of the contralateral inferior colliculus, however, does not produce complete deafness or completely eliminate conditioned responses to sounds. Sounds above $65 \mathrm{~dB}$ can still be detected.

Partial lesions of the contralateral inferior colliculus do not produce marked elevations in absolute thresholds for noise. The reason for this is likely related to the topographic organization of the inferior colliculus and the broad spectrum of acoustic 
energy inherent in the noise stimulus. Electrophysiological studies indicate that the inferior colliculus is organized in a "tonotopic" fashion, i.e., different sound frequencies are represented as isofrequency contours located in different places within the central nucleus of the inferior colliculus (Brunso-Bechtold, et al., 1981; Ryugo, et al., 1981; Zook \& Casseday, 1982; Oliver, 1984a). In the rat high sound frequency contours are represented ventromedially and low frequency contours are represented dorsolaterally with frequency-specific contours within the spectrum arranged sequentially from a high to low (Osen, 1972; Schreiner \& Langner, 1997; Malmierca, et al., 2008). Thus, partial lesions of the inferior colliculus leave some frequency specific areas intact while destroying other frequency specific areas. A noise stimulus, such as the one used in the present study, contains energy across a wide range of sound frequencies. A partial lesion of inferior colliculus, therefore, would not be expected to disrupt processing of all of the sound frequencies contained within the noise stimulus. Processing only part of the acoustic energy within the stimulus would be sufficient to maintain near normal thresholds for hearing. To determine whether or not partial lesions produced frequency specific deficits it would be necessary to determine absolute thresholds for tones or narrow band noises and to compare these with normal thresholds across the same frequency range.

The deficits produced by complete lesions of the inferior colliculus raise the question of which pathways are responsible for the elevated thresholds. Clearly the inferior colliculus provides a major stepping-stone along the path from lower brainstem nuclei to the auditory forebrain including the thalamus (medial geniculate body) and its ascending projections to the auditory cortex. However, the threshold shifts produced by 
midbrain lesions cannot be attributed to a disconnection of the pathway to auditory cortex. Bilateral ablation of auditory cortex in rats as well as other mammals fails to produce any persistent elevation in absolute thresholds for detecting the presence of sounds in the environment (Kelly \& Glazier, 1978; Kelly, 1980; Kavanagh \& Kelly, 1988; Burke \& Kelly, 2009). Indeed, bilateral lesions of the MGB itself fail to produce deficits in the ability to localize sounds in space at moderate sound pressure levels even though deeper lesions that extend into the brachium of the inferior colliculus $(B I C)$ and parts of the lateral tegmentum do produce profound deficits (Kelly \& Judge, 1985).

Thus, a disconnection of the most direct route from colliculus to cortex cannot account for the deficits observed in the present study. One possible forebrain pathway that might contribute to the deficits, however, is that mediated by the posterior intralaminar nucleus (PIN) located medially to the MGB, described by Doron \& LeDoux (2000). This nucleus receives auditory projections from the inferior colliculus and provides a route from the auditory midbrain to the lateral amygdala, a structure that is known to be critical in mediating conditioned emotional responses to sounds (LeDoux, 2003).

\subsection{Contralateral Pathway}

In mammals, most sensory and motor systems are organized in a contralateral fashion. The left brain receives input from the right side of the body, and controls the muscles on the right side of the body. This contralateral representation is documented in the visual, somatosensory and skeletal motor system. The results of our experiment confirm a similar pattern of a contralateral representation in the auditory system. 
Lesions of the contralateral inferior colliculus produced more severe behavioural deficits in auditory sensitivity than the equivalent lesions of the ipsilateral inferior colliculus. Thus, the maintenance of normal levels of sensitivity to sounds depends almost exclusively on the contralateral projection pathways from the lower brainstem auditory nuclei. This result is consistent with both anatomical and electrophysiological data regarding the organization of the auditory brainstem. First, the cochlear nucleus provides a large direct contralateral projection to the inferior colliculus on the opposite side of the brain (Faye-Lund, 1986; Coleman \& Clerici, 1987). In the rat the vast majority of efferent neurons from the cochlear nucleus to the inferior colliculus have a contralateral projection pattern (Faye-Lund, 1986; Coleman \& Clerici, 1987). The superior olivary complex also contributes to contralateral representation. For example the medial superior olive, which normally projects to the ipsilateral inferior colliculus is driven primarily by acoustic stimulation that favors the contralateral ear. The lateral superior olive, which is excited by ipsilateral stimulation and inhibited by contralateral stimulation, has both ipsilateral and contralateral projections to inferior colliculus, but its crossed projections are excitatory (glutamatergic) and its ipsilateral projections are inhibitory (glycinergic). Thus the lateral superior olive also contributes to a contralateral representation (Adams, 1979; Brunso-Bechtold, et al., 1981; Masterton \& Imig, 1984; Coleman \& Clerici, 1987). The decussating connections of the superior olivary complex have been referred to as an "acoustic chiasm" because they result in a contralateral representation of auditory space corresponding to the contralateral representation of visual space by way of the optic chiasm (Glendenning, et al., 1981). The nuclei of the lateral lemniscus also preserve and enhance the contralateral representation. The ventral 
nucleus of the lateral lemniscus with an exclusively ipsilateral projection to inferior colliculus preserves the contralateral organization already established by the superior olivary complex, whereas the dorsal nucleus of the lateral lemniscus actually enhances the contralateral representation through a crossed inhibitory (GABAergic) projection to the inferior colliculus via the commissure of Probst (Shneiderman, et al., 1988; Glenn \& Kelly, 1992; Li \& Kelly, 1992; Kelly, et al., 1996; Kidd \& Kelly, 1996; Kelly \& Li, 1997; Zhang, et al., 1998; van Adel, et al., 1999; Kelly \& Kidd, 2000; Kelly, et al., 2009).

Physiological recording from single neurons in the rat's inferior colliculus show that most cells are driven by acoustic stimulation of the contralateral ear (Flammino \& Clopton, 1975; Clopton \& Silverman, 1977; Kelly, et al., 1991; Sally \& Kelly, 1992; Kelly \& Li, 1997; Kelly \& Zhang, 2002). In some cases the neurons are excited by contralateral stimulation and are unaffected by ipsilateral stimulation. In the vast majority of cases, however, the neurons are excited by contralateral stimulation and inhibited by ipsilateral stimulation reflecting the binaural interaction pattern established initially in the superior olivary complex and reinforced by crossed projections via the commissure of Probst (van Adel, et al., 1999). Other neurons are excited by stimulation of either ear and have interaction patterns that reflect activity of cells in the medial superior olive. In some cases the binaural interaction patterns are likely formed locally within the inferior colliculus itself. But, taken together these responses lead to a much greater excitatory activity in the inferior colliculus opposite the ear to which the sound stimulus is delivered. Contralateral lesions of the inferior colliculus would be expected to greatly reduce the excitatory drive produced by stimulation of the opposite ear resulting in a 
much greater elevation of absolute thresholds than that found following ipsilateral lesions of comparable size and position.

\subsection{Contribution of DNLL}

One surprising result of the present study was the finding that a complete lesion of the contralateral inferior colliculus alone did not produce the most profound elevation of absolute thresholds. Inclusion of the contralateral dorsal nucleus of the lateral lemniscus resulted in a significant further elevation of approximately $15 \mathrm{~dB}$ in the threshold for detecting a noise stimulus. Following lesions that include both contralateral DNLL and IC, absolute thresholds were elevated from around $20 \mathrm{~dB}$ for normal rats to around $80 \mathrm{~dB}$ for rats with lesions.

This result implies that destruction of the inferior colliculus alone is not enough to produce a complete insensitivity to sounds even though it is commonly characterized as an obligatory synapse in the auditory pathway (Aitkin \& Phillips, 1984; Winer \& Schreiner, 2005). It is not clear which extra-collicular pathways are responsible for the additional deficit produced by inclusion of DNLL in the lesion. There have been reports in the literature, however, of pathways that project to the auditory forebrain without a synaptic interruption in the inferior colliculus. One of these is the central acoustic tract of Papez, which arises in the vicinity of the lateral lemniscus and projects to the auditory thalamus (Papez, 1929). However, the detailed anatomy of this possible pathway in the rat has not been adequately investigated. Another possible projection path around the inferior colliculus is the ascending reticular activating system. It has been shown that auditory stimulation can produce changes in the electrical activity of the forebrain even 
after lesions that destroy the input to inferior colliculus or disconnect the output of the inferior colliculus by transection of its brachium (Starzl, et al., 1951; Galambos, et al., 1961; Nieder \& Strominger, 1965; Masterton, et al., 1968; Strominger \& Oesterreich, 1970). However, the existence of these projections and their precise connections within the central auditory system of the rat are not well enough established to allow any firm conclusions about their involvement in maintaining normal auditory sensitivity.

\subsection{Functional Recovery}

The results of the present study showed no obvious functional recovery in auditory thresholds following the lesions. Deficits persisted throughout the 3 week period of postoperative testing. Also, anatomical tract tracing showed no evidence of change in the underlying patterns of axonal projections to inferior colliculus from lower brainstem nuclei. However, the results do not exclude the possibility of functional recovery following lesions of inferior colliculus during early development. Unilateral ablation of inferior colliculus in infant rat pups on postnatal day 3 (before the onset of hearing around postnatal day 14) results in a reorganization of brainstem projections to the remaining inferior colliculus in adults (Okoyama, et al., 1995a, 1995b; Ito, et al., 2008). The medial superior olive, which normally has an ipsilateral projection to inferior colliculus in adults, gives rise to an abberent contralateral projection in adults that received a complete unilateral lesion of inferior colliculus during early development. This raises the possibility of functional recovery in rats with early lesions. 


\section{Conclusion}

1) The present study provides behavioral data that confirm the expectation from anatomical and physiological evidence that the inferior colliculus plays an important role in hearing and is necessary for such fundamental functions as maintenance of sensitivity to sounds in a situation that requires learning a conditioned avoidance response.

2) The contralateral projection pathways to the inferior colliculus are the ones primarily responsible for maintaining normal thresholds for hearing. Contralateral lesions produce significant elevations in thresholds whereas equivalent ipsilateral lesions have little or no effect. The result is consistent with anatomical and physiological data showing contralateral representation of sound at the level of the auditory midbrain.

3) Complete destruction of the contralateral inferior colliculus does not eliminate all learned responses to sound. Additional damage to the contralateral dorsal nucleus of the lateral lemniscus results in a significantly greater elevation of absolute threshold. This effect is likely produced by disruption of auditory pathways that bypass the inferior colliculus, but the details of the projection remain unknown. 
Table 1: Summary of lesions and thresholds for individual animals.

\begin{tabular}{|c|c|c|c|c|c|c|}
\hline ANIMAL & LESION & ICX & ICD & ICC & DNLL & MAT \\
\hline 1 & NORMAL & 0 & 0 & 0 & O & 11.94 \\
\hline 2 & NORMAL & 0 & 0 & 0 & 0 & 15.81 \\
\hline 3 & NORMAL & 0 & 0 & 0 & 0 & 24.84 \\
\hline 41 & NORMAL & 0 & 0 & 0 & 0 & 31.67 \\
\hline 42 & NORMAL & 0 & 0 & 0 & 0 & 34.58 \\
\hline 43 & NORMAL & 0 & 0 & 0 & 0 & 18.75 \\
\hline 44 & NORMAL & 0 & 0 & 0 & 0 & 9.17 \\
\hline 16 & IPSI. & 0 & 0 & 0 & 0 & 22.08 \\
\hline 17 & IPSI. & 0 & 0 & 0 & 0 & 22.50 \\
\hline 18 & IPSI. & 0 & 0 & 0 & 0 & 24.58 \\
\hline 28 & IPSI. & 0 & 0 & 0 & 0 & 28.64 \\
\hline 29 & IPSI. & 0 & 0 & 0 & 0 & 32.27 \\
\hline 11 & CONTRA. & 0 & 0 & 0 & 0 & 28.33 \\
\hline 12 & CONTRA. & 0 & 0 & 0 & 0 & 35.83 \\
\hline 13 & CONTRA. & 0 & 0 & 0 & 0 & 32.92 \\
\hline 14 & CONTRA. & 0 & 0 & 0 & 0 & 37.08 \\
\hline 15 & CONTRA. & 0 & 0 & 0 & 0 & 29.17 \\
\hline 24 & CONTRA. & 0 & 0 & 0 & 0 & 85.45 \\
\hline 25 & CONTRA. & 0 & 0 & 0 & 0 & 87.05 \\
\hline 26 & CONTRA. & 0 & 0 & 0 & 0 & 87.73 \\
\hline 31 & CONTRA. & 0 & 0 & 0 & 0 & 76.59 \\
\hline 32 & CONTRA. & 0 & 0 & 0 & 0 & 82.05 \\
\hline 33 & CONTRA. & $\bullet$ & 0 & 0 & $\bullet$ & 71.14 \\
\hline 34 & CONTRA. & 0 & 0 & 0 & 0 & 65.00 \\
\hline 35 & CONTRA. & 0 & 0 & 0 & 0 & 77.73 \\
\hline 36 & CONTRA. & 0 & 0 & 0 & 0 & 65.23 \\
\hline 37 & CONTRA. & 0 & 0 & 0 & 0 & 56.82 \\
\hline 38 & CONTRA. & 0 & 0 & 0 & 0 & 68.86 \\
\hline
\end{tabular}


Table 2. Mann-Whitney U pairwise comparisons of lesion groups.

In this and subsequent Mann-Whitney $\mathrm{U}$ comparison tables, statistics are for rank ordered mean threshold data for each group. Sample sizes are shown in parentheses beside the group.

\begin{tabular}{|c|c|c|c|c|}
\hline Paired comparison & $\begin{array}{c}\text { Sum of } \\
\text { ranks }\end{array}$ & $U$ & $Z$ & $p$ (two-tailed) \\
\hline Normal (7) & 40 & \multirow{2}{*}{12.00} & \multirow{2}{*}{.893} & \multirow{2}{*}{.372 (n.s.) } \\
\hline Ipsilateral (5) & 38 & & & \\
\hline Normal (7) & 33 & \multirow{2}{*}{5.00} & \multirow{2}{*}{3.055} & \multirow{2}{*}{.001} \\
\hline Contralateral (16) & 243 & & & \\
\hline Ipsilateral (5) & 18 & \multirow[b]{2}{*}{3.00} & \multirow{2}{*}{3.408} & \multirow[b]{2}{*}{.002} \\
\hline Contralateral (16) & 213 & & & \\
\hline
\end{tabular}


Table 3. Mann-Whitney $U$ pairwise comparisons of threshold in rats with partial and complete lesions of the ICc ipsilateral or contralateral.

\begin{tabular}{|c|c|c|c|c|}
\hline Paired comparison & $\begin{array}{l}\text { Sum of } \\
\text { ranks }\end{array}$ & $U$ & $Z$ & $p$ (two-tailed) \\
\hline Ipsilateral Partial (2) & 3 & \multirow{2}{*}{0.00} & \multirow{2}{*}{1.732} & \multirow{2}{*}{.083 (n.s.) } \\
\hline Ipsilateral Complete(3) & 12 & & & \\
\hline Contralateral Partial (5) & 15 & \multirow{2}{*}{0.00} & \multirow{2}{*}{3.115} & \multirow{2}{*}{.002} \\
\hline Contralateral Complete (11) & 121 & & & \\
\hline
\end{tabular}


Table 4. Mann-Whitney $U$ pairwise comparisons of cases with intact or damaged DNLL in addition to complete ICc lesions.

\begin{tabular}{|c|c|c|c|c|}
\hline Paired comparison & $\begin{array}{l}\text { Sum of } \\
\text { ranks }\end{array}$ & $U$ & $Z$ & $p$ (two-tailed) \\
\hline Ipsilateral DNLL intact (1) & 3 & \multirow{2}{*}{0.00} & \multirow{2}{*}{1.225} & \multirow{2}{*}{.221 (n.s.) } \\
\hline Ipsilateral DNLL damaged (2) & 3 & & & \\
\hline Contralateral DNLL intact (3) & 6 & \multirow{2}{*}{0.00} & \multirow{2}{*}{2.449} & \multirow{2}{*}{.014} \\
\hline Contralateral DNLL damaged (8) & 243 & & & \\
\hline
\end{tabular}


Table 5 : Descriptive statistics. Categorized by lesion, mean absolute thresholds for detecting the presence of noise.

\begin{tabular}{lcccccc}
\hline \multicolumn{1}{c}{ Lesion Group } & $n$ & Mean & Median & St. Dev. & $\begin{array}{c}\text { Confidence Interval }^{\mathrm{a}} \\
\text { Lower Bound Upper Bound }\end{array}$ \\
\hline Normal & 7 & 20.97 & 18.75 & 9.72 & 11.97 & 29.96 \\
& & & & & & \\
Ipsilateral & 5 & 26.01 & 24.58 & 4.35 & 20.60 & 31.42 \\
$\quad$ Partial ICc & 2 & 22.29 & 22.29 & .30 & 19.62 & 24.96 \\
Complete ICc & 3 & 28.50 & 28.64 & 3.85 & 18.94 & 38.05 \\
$\quad$ DNLL intact & 1 & 24.58 & - & - & - & - \\
$\quad$ DNLL damaged & 2 & 30.45 & 30.45 & 2.57 & 26.89 & 34.01 \\
& & & & & & \\
Contralateral & 16 & 61.69 & 67.04 & 21.97 & 49.98 & 73.39 \\
Partial ICc & 5 & 32.67 & 32.92 & 3.89 & 27.83 & 37.50 \\
Complete ICc & 11 & 74.88 & 76.59 & 10.26 & 67.99 & 81.78 \\
$\quad$ DNLL intact & 3 & 62.36 & 65.00 & 4.77 & 50.52 & 74.21 \\
$\quad$ DNLL damaged & 8 & 79.58 & 79.90 & 7.18 & 73.57 & 85.58 \\
\hline
\end{tabular}

${ }^{a}$ Results for $95 \%$ confidence interval on the mean 
Figure 1: The ascending auditory pathway of the rat. This figure shows the location of nuclei in the central auditory system. It also illustrates the connectivity of the principal nuclei in: the cochler nucleus $(\mathrm{CN})$, dorsal cochlear nucleus (DCN), ventral cochlear nucleus (VCN), superior olivary complex (SOC), medial superior olive (MSO), lateral superior olive (LSO), nuclei of lateral lemniscus (nLL), ventral nucleus of lateral lemniscus (VNLL), dorsal nucleus of lateral lemniscus (DNLL), inferior colliculus (IC), central nucleus of inferior colliculus (ICc), external nucleus of inferior colliculus (ICx), dorsal nucleus of inferior colliculus (ICd), brachium of inferior colliculus (BIC), medial geniculate body (MGB), ventral division of the medial geniculate body (MGBv), medial division of the medial geniculate body (MGBm), dorsal division of the medial geniculate body (MGBd), and auditory cortex (AC). This schematic has been modified with permission from Elsevier, in Malmierca \&.Merchán (2004) 


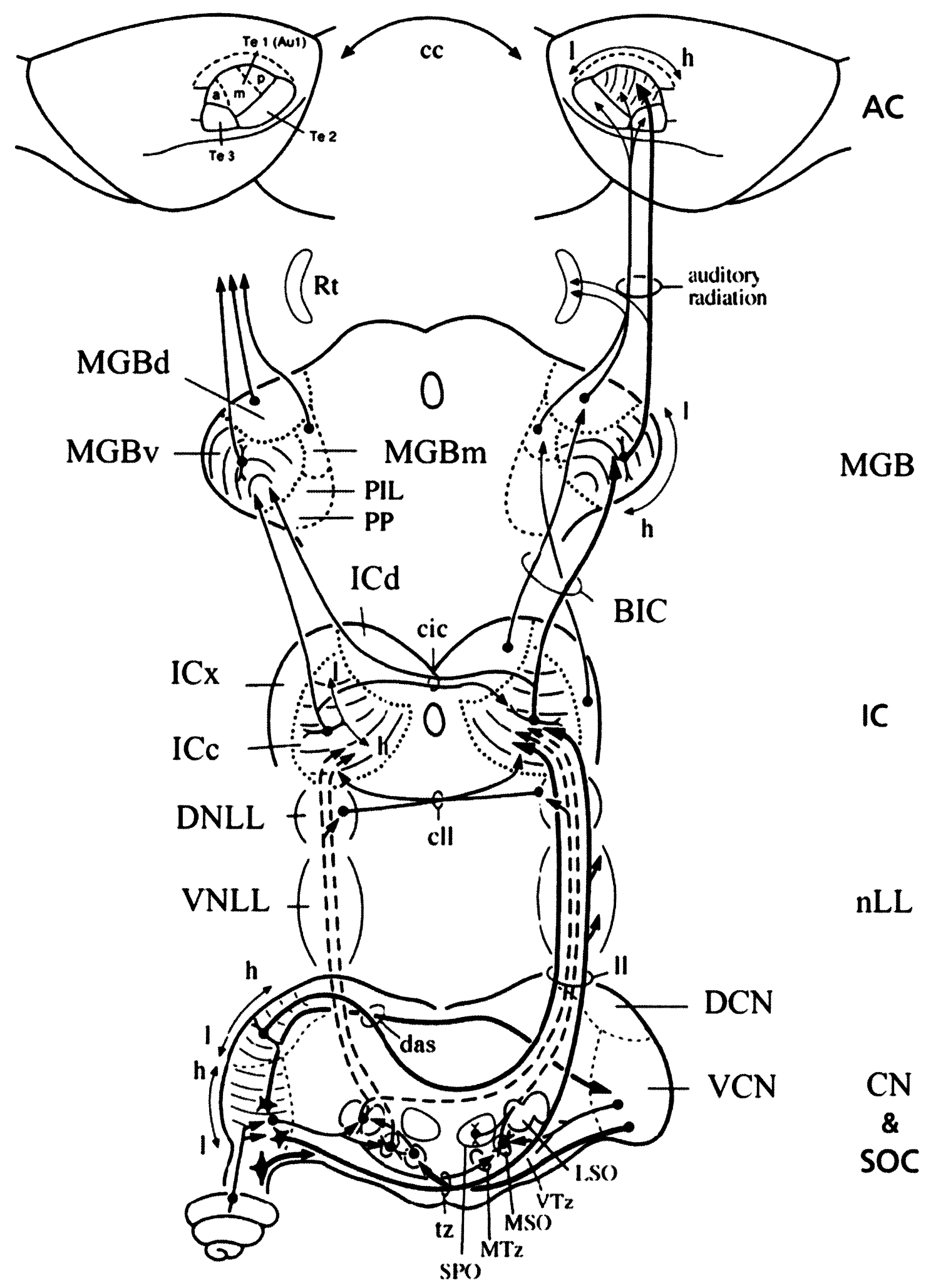


Figure 2 : Central nucleus of inferior colliculus (ICc, CN) in six different species of experimental animals in Nissl preparation, used with permission from Springer, in (Casseday, et al., 2005): (A) In the mustached bat, Pteronotus p. parnellii, (Zook et al.1985). (B) The barn owl, Tyto alba, (Takahashi and Konishi 1988). (C) Rat (Faye-Lund and Osen 1985). (D) The cat central nucleus (CN) (Winer et al. 1998). (E) The rhesus monkey (CN) (Fitzpatrick, 1975). (F) Human (Geniec \& Morest, 1971). 


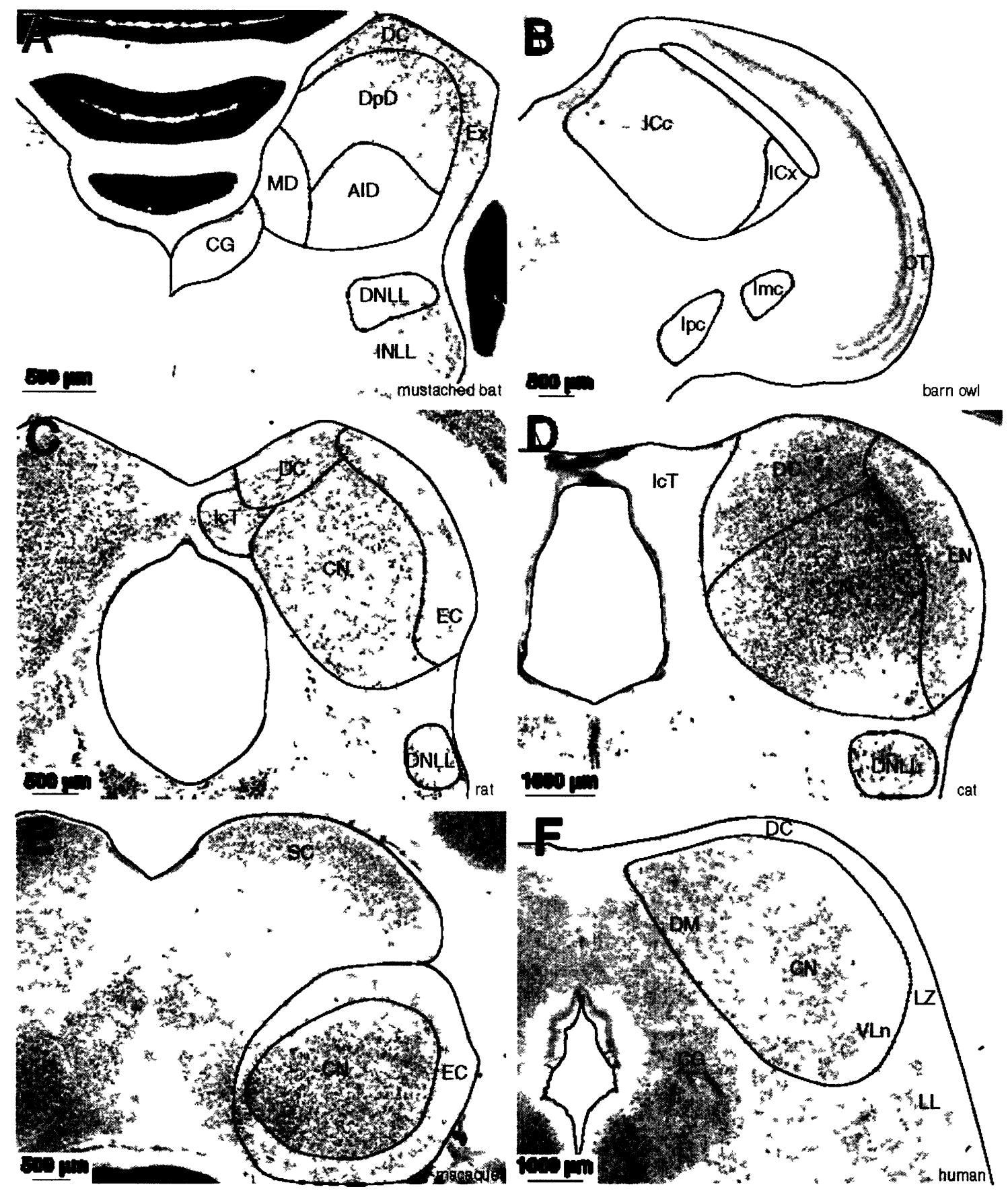


Figure 3: The superior olivary complex and the circuits of the principal nuclei. (A) Schematic drawing showing the location of the major nuclei of the SOC. $(\mathbf{B}, \mathbf{C})$ Schematic drawings showing the major inputs to the MSO and the LSO. In this and subsequent drawings, arrows indicate major projections, with line thickness indicating relative size. The major neurotransmitter (or the postsynaptic effect) is indicated by the legend. GABA and glycine are generally inhibitory; the excitatory neurotransmitter(s) are less well known but for many pathways are believed to be glutamate or a related substance. The midline is represented by a thin, dashed vertical line. Used with permission from Springer, in Schofield (2005) 
A SOC nuclei

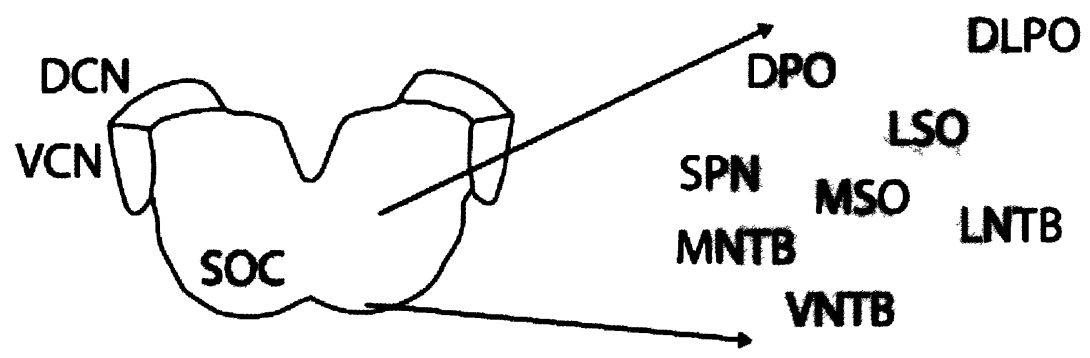

B MSO
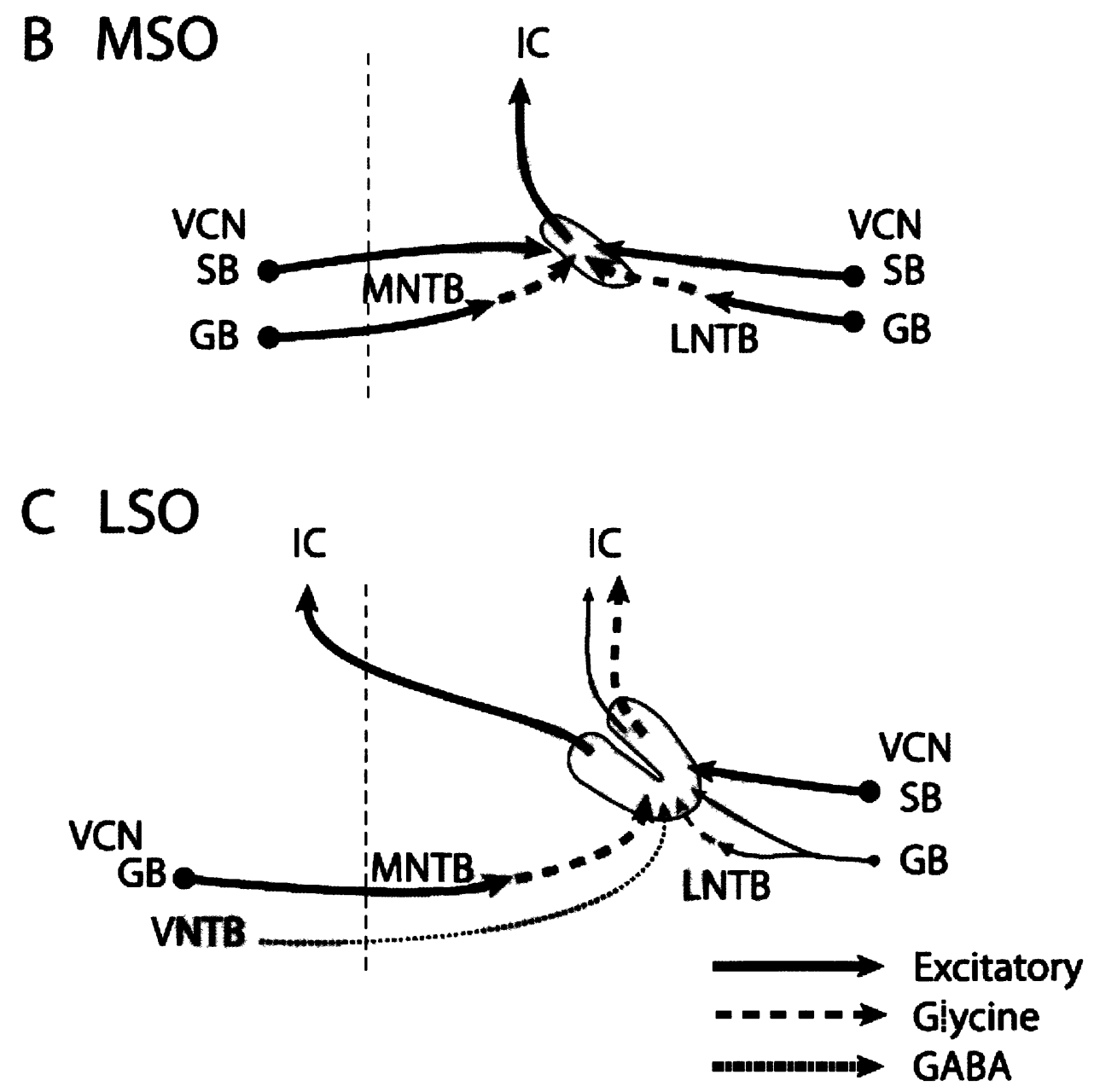
Figure 4: Lateral lemniscal nuclei and their connections. (A) Schematic diagram of the nLL. (B-D) Schematic diagrams show the inputs and projections to inferior colliculus projections of the two major subdivisions of the lateral lemniscus, the VNLL (B), and the DNLL (D). Not discussed is (C). Used with permission from Springer, in Schofield (2005). 
A Lemniscal nuclei

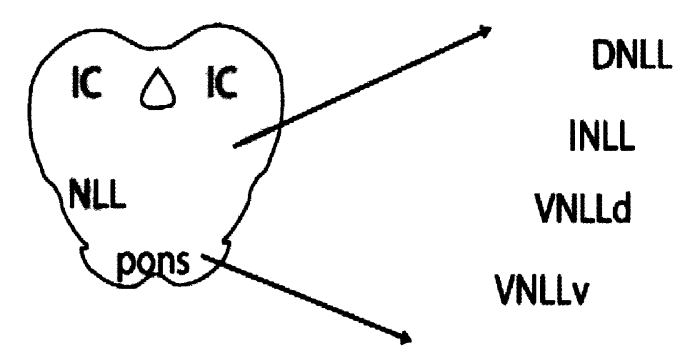

B VNLL
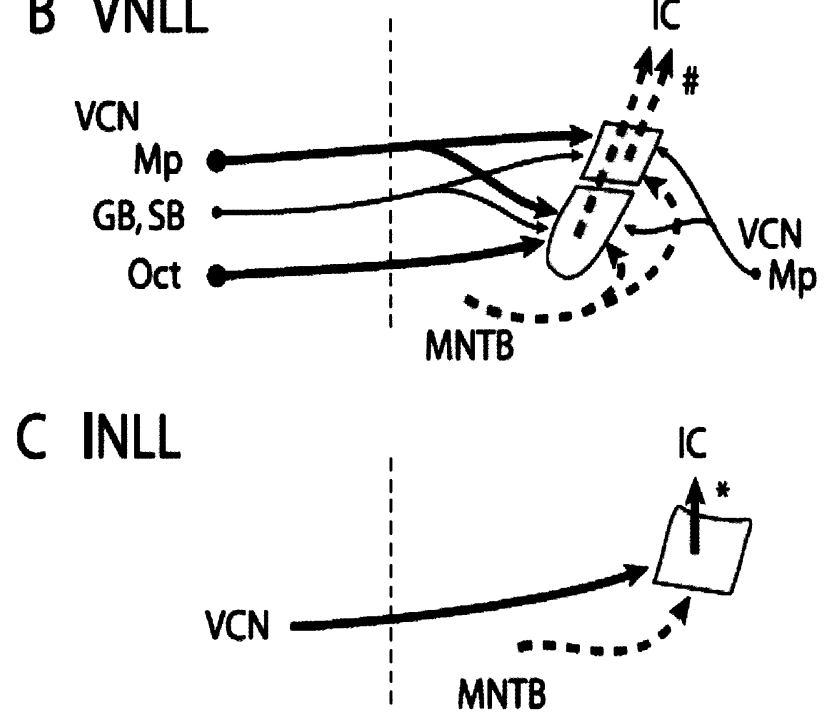

D DNLL
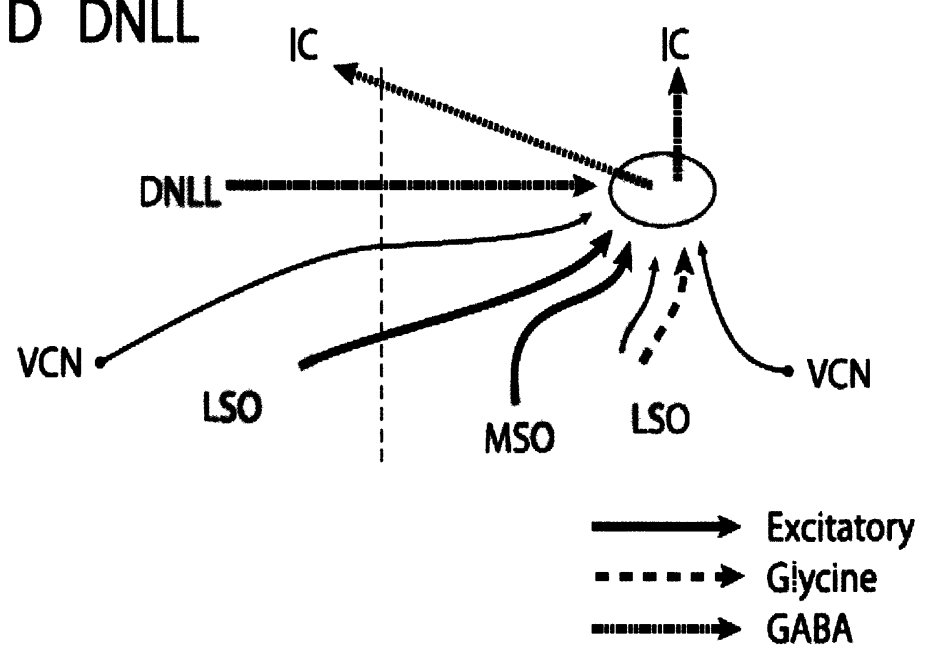
Figure 5: Summary of monaural pathways to the IC. (A) Direct

projections from the cochlear nuclei. (B) Indirect monaural projections

through the SOC and nLL. Used with permission from Springer, in Schofield (2005). 
A Direct monaural pathways

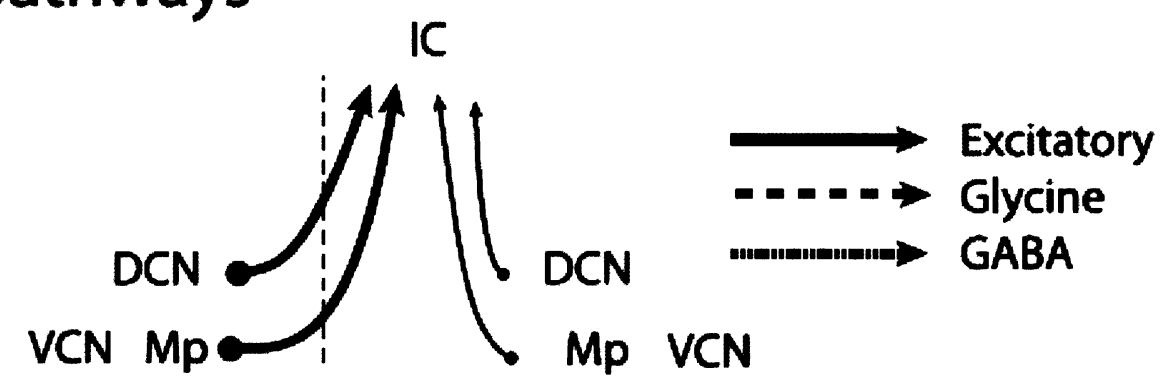

B Indirect monaural

IC pathways

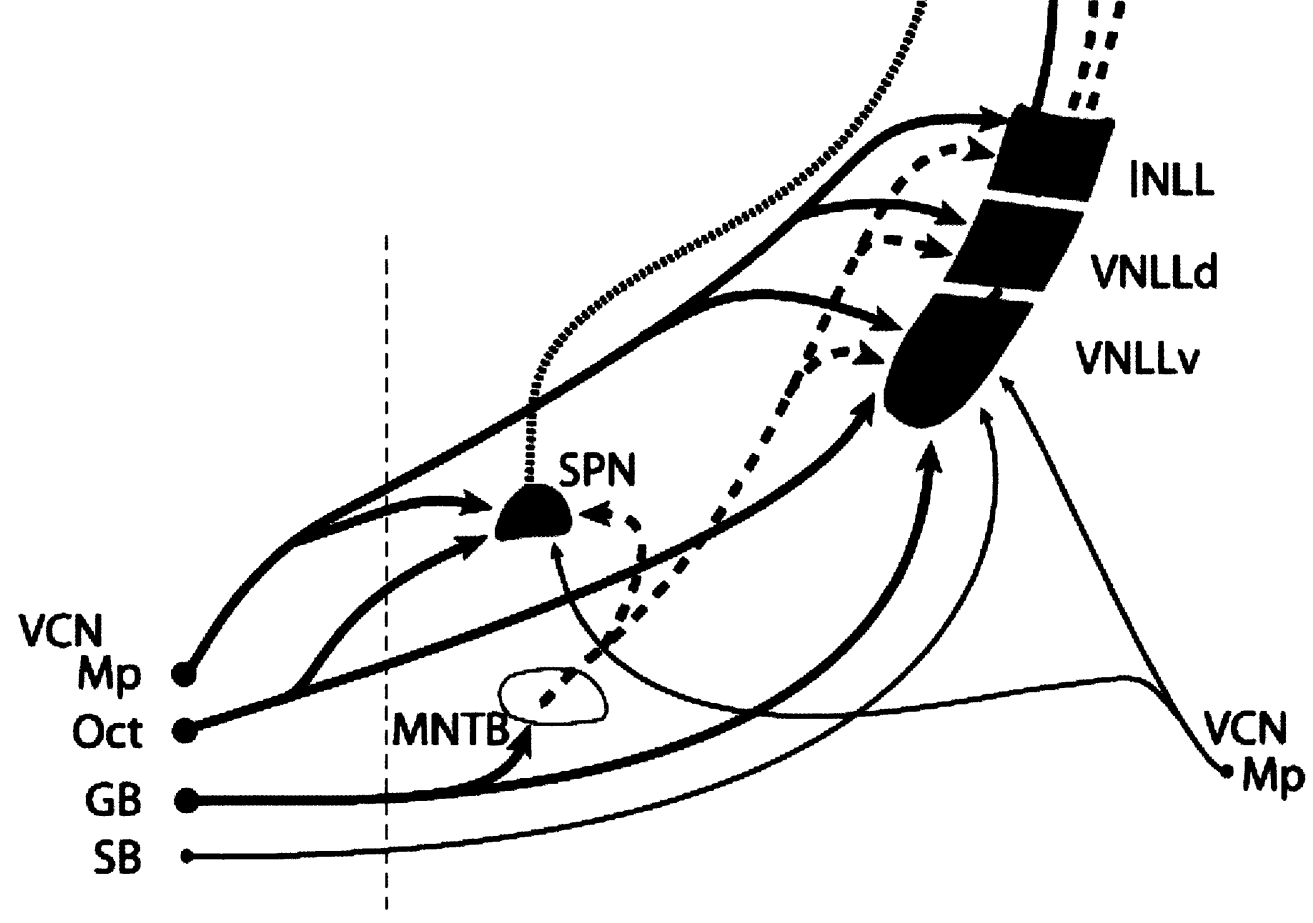


Figure 6: Summary of binaural pathways pathways through the SOC and the nLL to the inferior colliculus. Used with permission from Springer, in Schofield (2005). 

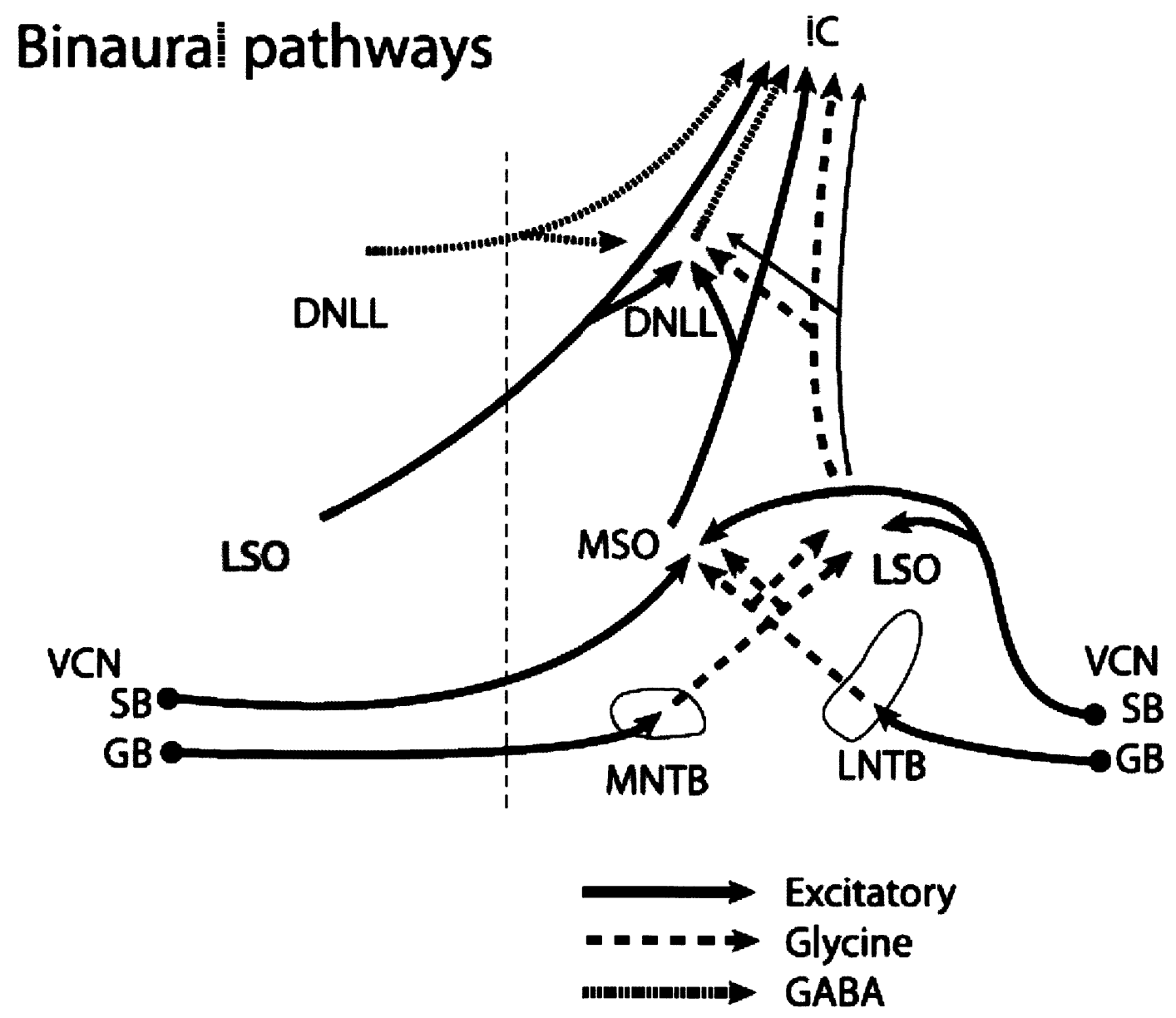
Figure 7: A schematic overview of the behavioural apparatus employed for the experiment. The schematic shows the location of the lick spout inside a small stainless steel mesh test cage (A). A loudspeaker (B), was suspended $70 \mathrm{~cm}$ in front of the test cage. Water was delivered by a syringe pump (C), located outside a sound-attenuated chamber that housed the cage and speaker. Sounds were generated by a Tucker-Davis digital signal processing module (D), and passed through a power amplifier (E). The timing of the whitenoise bursts, water reinforcement and shock delivery was controlled by the Tucker-Davis System 3 RP2 module and computer (F) with custom software. 


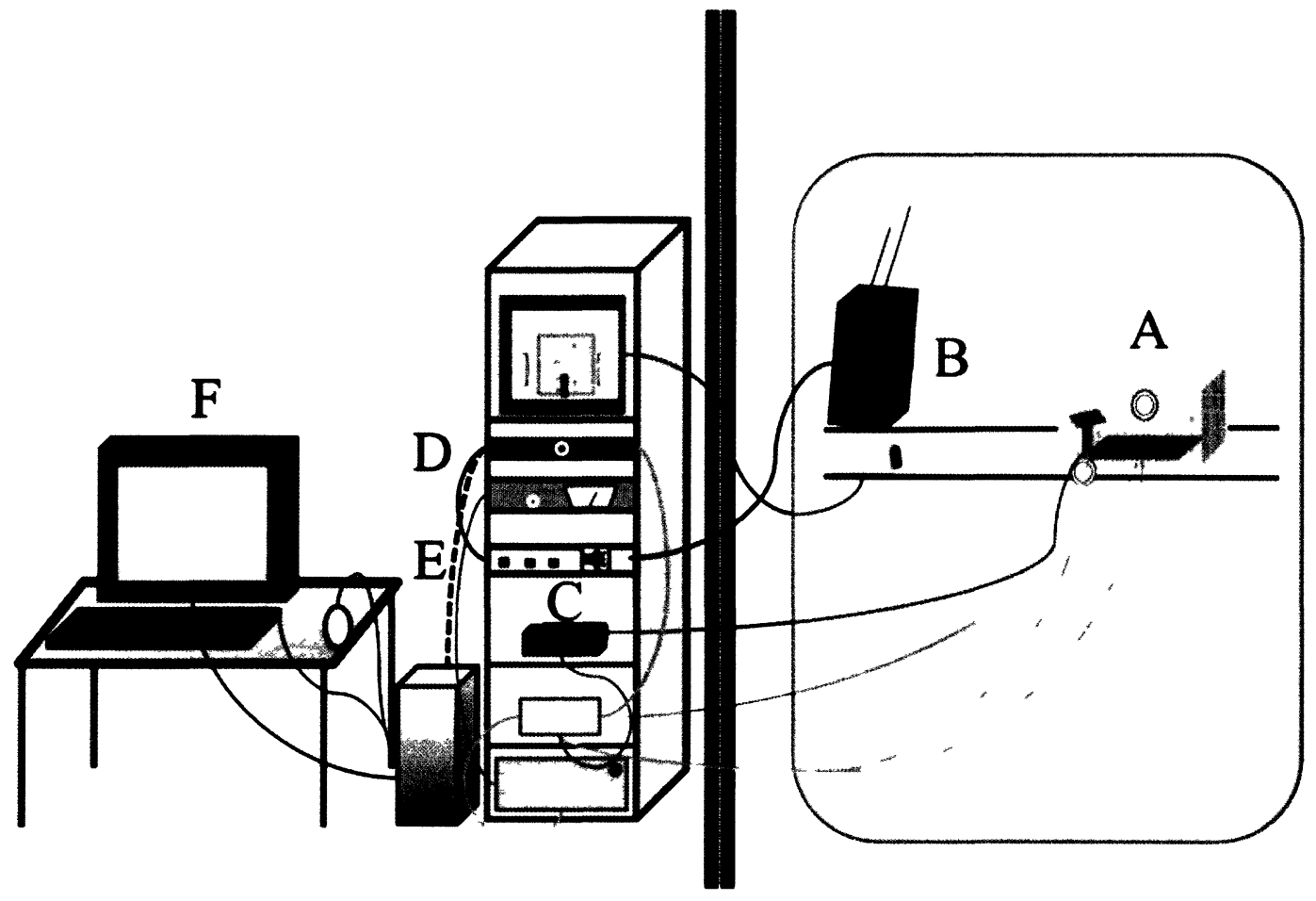


Figure 8: Stimulus presentation. Performance during uninterrupted trials was monitored by sampling contact with the spout during regularly occurring safe periods. Responses to $200 \mathrm{~ms}$ broadband noise bursts were monitored by recording spout contact during warning periods that were introduced on a quasi-random basis. During safe and warning periods spout contact was determined during a $200 \mathrm{~ms}$ period (spout check) immediately before the end of each trial. The warning trials were followed by delivery of a brief avoidable mild shock delivered to the spout. Performance scores were calculated according to the formula:

\section{hit rate - (hit rate $x$ false alarm rate),}

where a hit was defined as withdrawal from the spout during a warning period, and a false alarm was defined as a withdrawal during the safe period. 


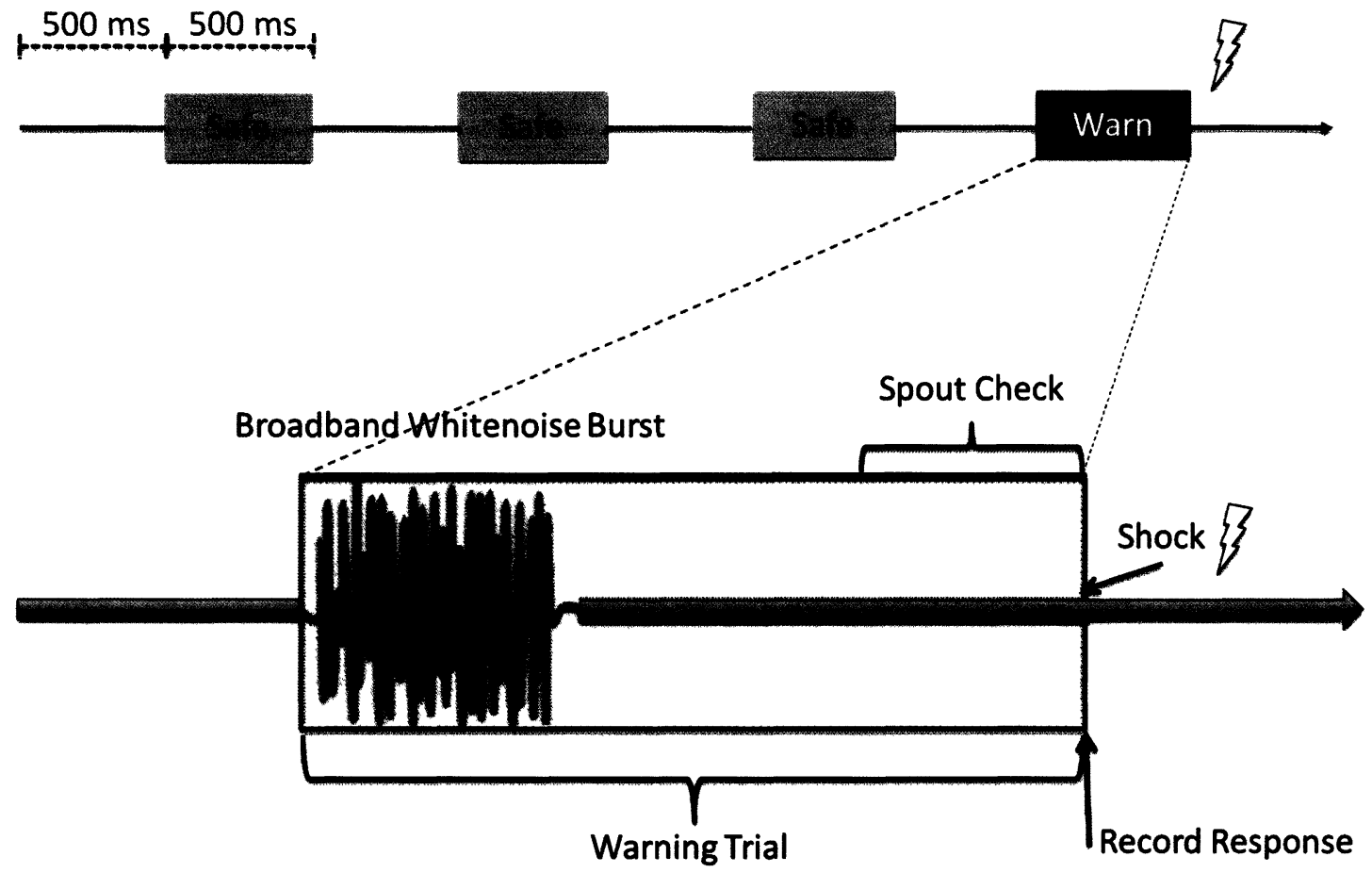


Figure 9: Schematic illustration of the retrograde tract tracing procedures used for each experimental group. Retrograde tract tracing was done with Fluoro-Gold injected unilaterally into the ICc. Three injections were made at an angle of 26 degrees relative to the saggital plane. The most medial injection was done at a depth of $1.8 \mathrm{~mm}$ and the lateral injections at $1.0 \mathrm{~mm}$ respectively. The illustration was re-constructed as a manipulation of Paxinos and Watson's Rat Brain in Stereotaxic Coordinates $\left(4^{\text {th }}\right.$ Edition), used with permission from Elsevier. 


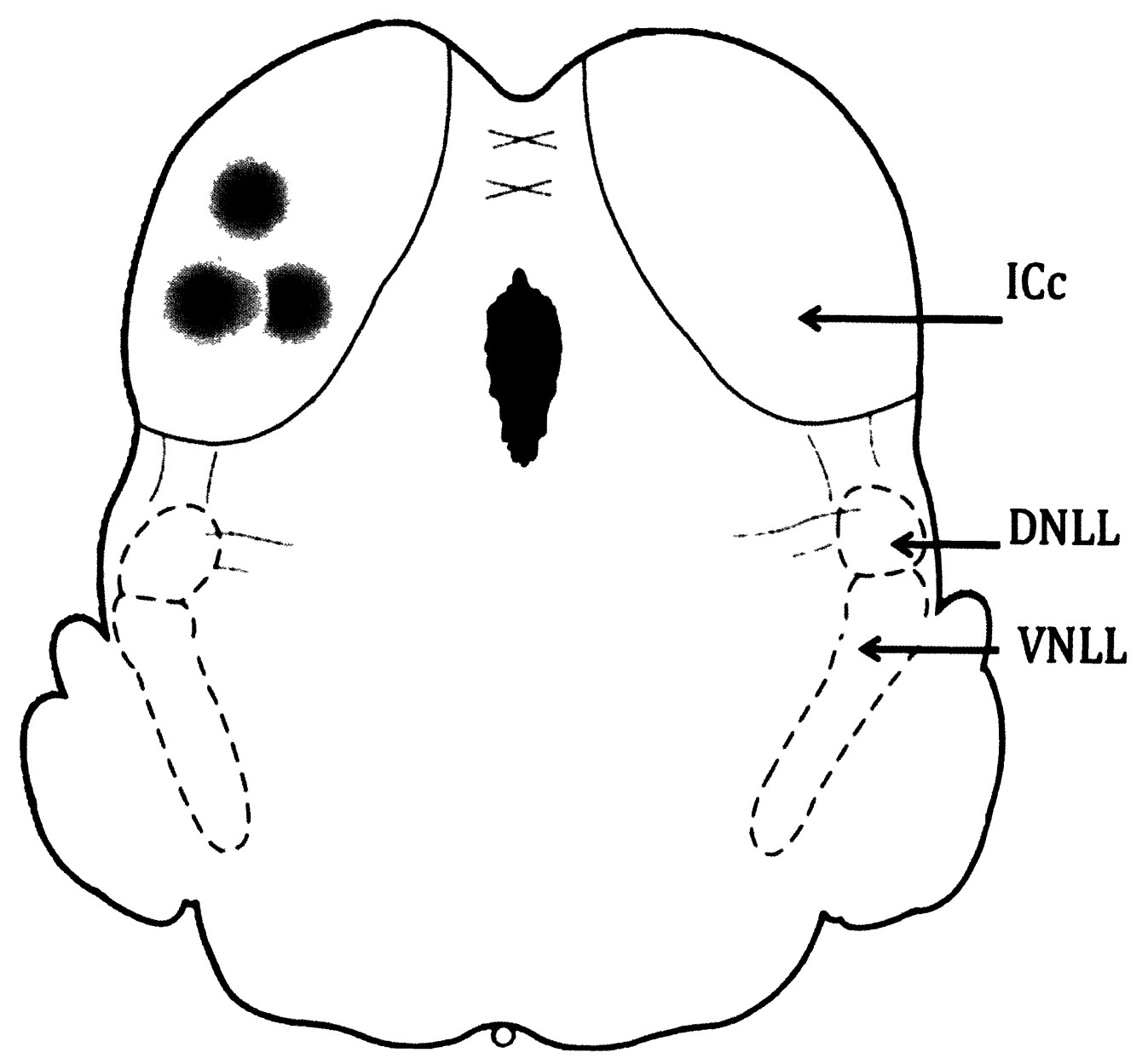


Figure 10: Psychophysical curve of normal animal (\#43). The animal was tested at intensities of 90 to $0 \mathrm{~dB}$ SPL by employing a method of descending limits. The figure shows a line to indicate the 0.5 avoidance score that is used to determine the animal's absolute threshold. By means of interpolation, this animal has a threshold of $18.75 \mathrm{~dB}$ SPL. 


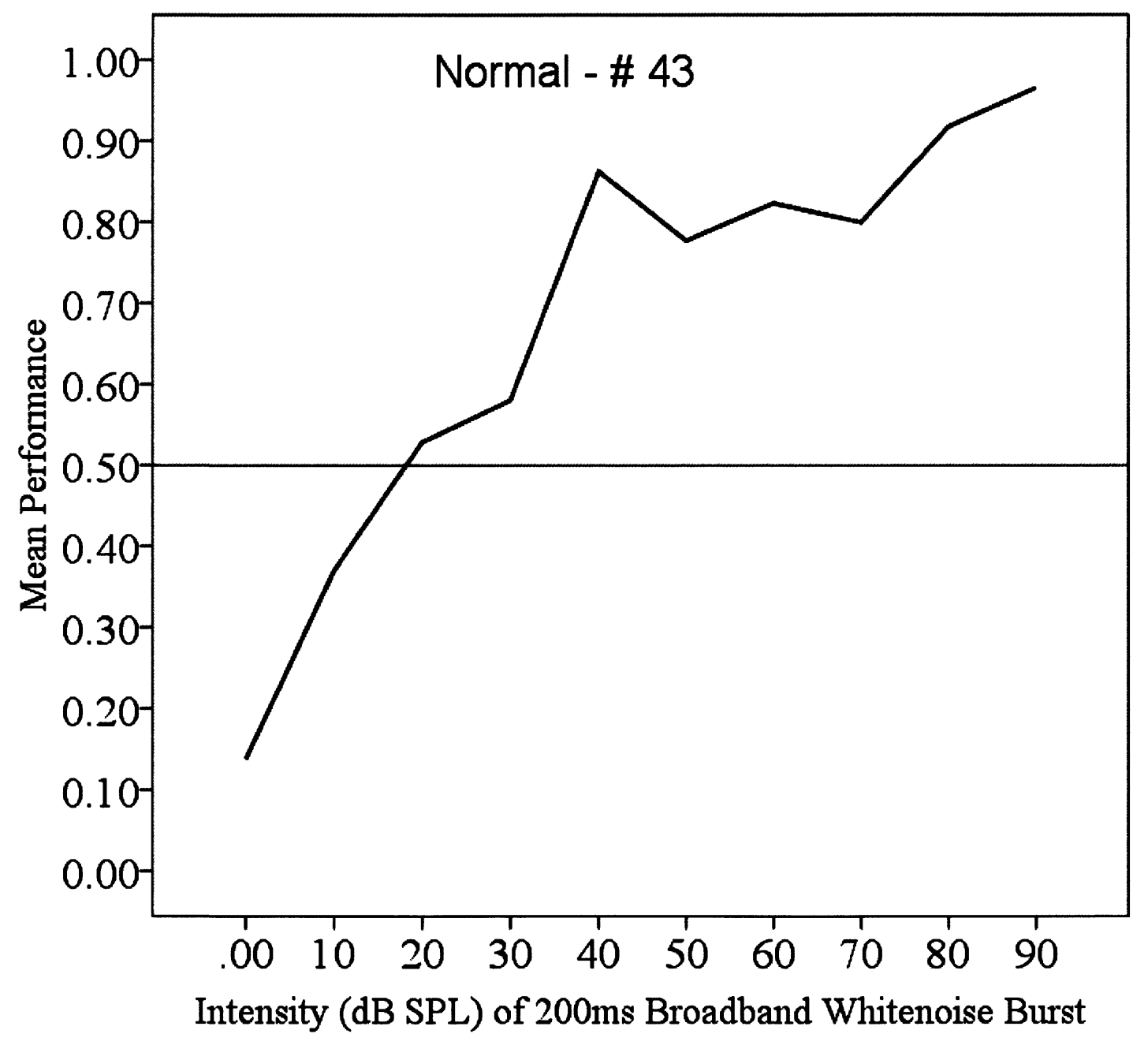


Figure 11: Mean psychophysical curve based on performance of all normal animals.

All 7 normal animals were tested at intensities of 90 to $0 \mathrm{~dB}$ SPL by employing descending limits. At the 0.5 criterion level, a line is superimposed for determining the mean absolute threshold. By linear interpolation, normal animals had a mean threshold $( \pm$ SD) of $20.97( \pm 9.72) \mathrm{dB}$ SPL. Error bars illustrated in this figure represent \pm SD of the animals' responses at each stimulus intensity. 


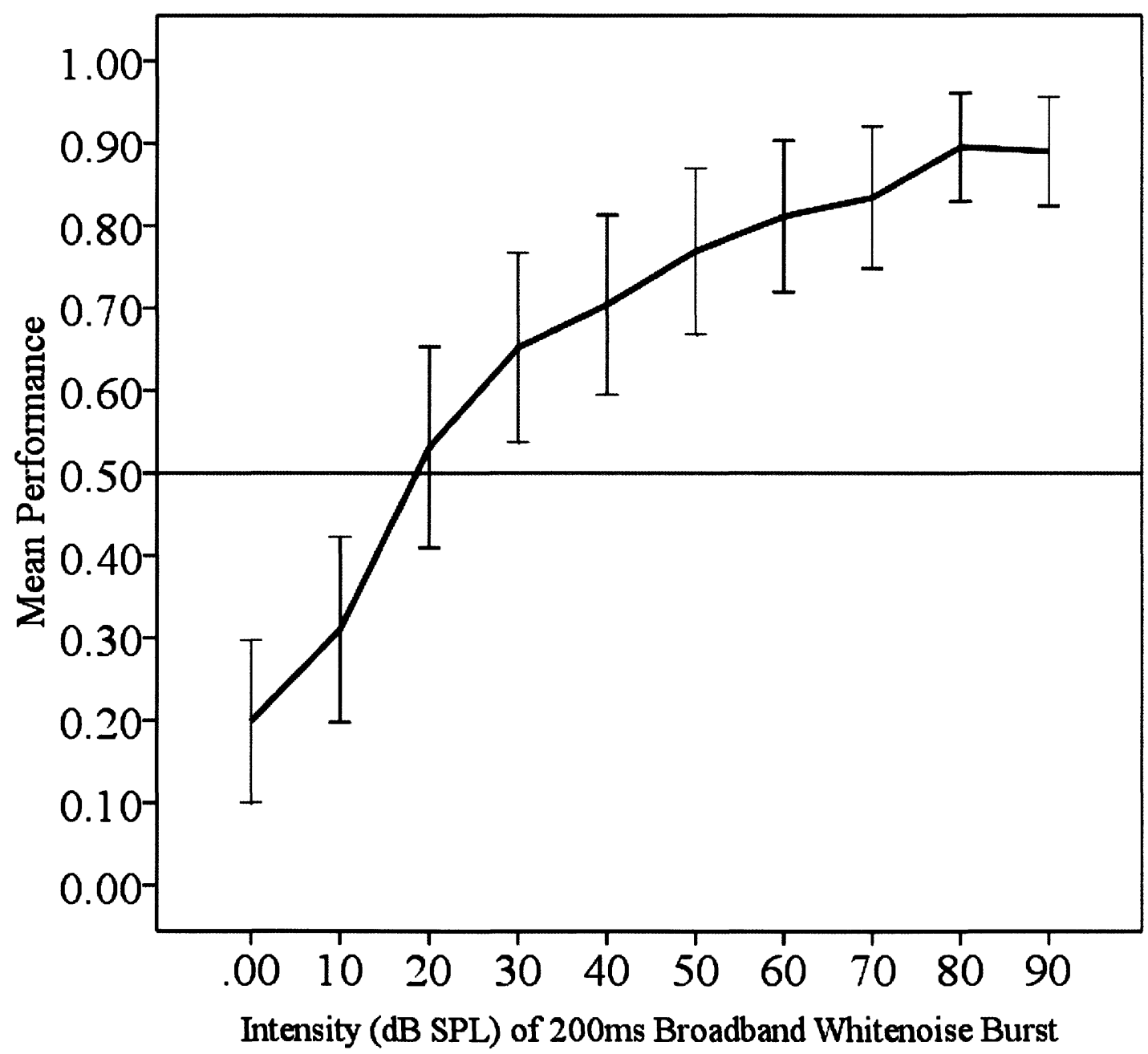

Error bars: +/- SD 
Figure 12: Efficacy of ear blocking. This figure shows the percentage of startle responses in untrained normal and untrained bilaterally ear-blocked animals to a noise at $90 \mathrm{~dB}$ SPL. The results of this particular study were recorded by a blind observer, and demonstrate that the ear blocks produce a profound hearing loss. This result was important for comparing the effects of ICc lesions placed ipsilateral or contralateral to a single unblocked ear. 
Startle Responses at $90 \mathrm{~dB}$ SPL

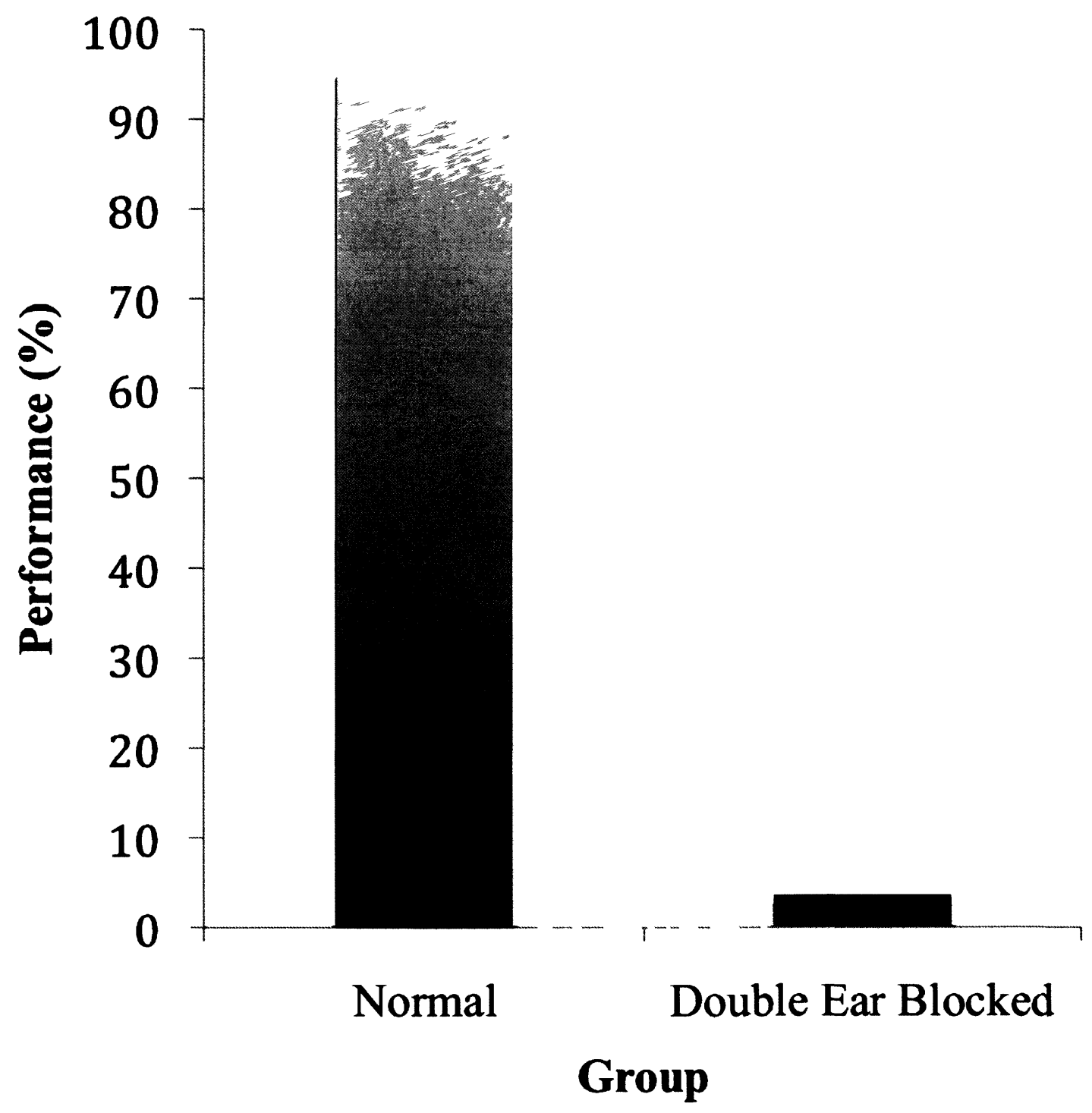


Figure 13: Anatomical organization of the auditory midbrain. Each animal in the study was examined histologically. This illustration was made to show in frontal sections, the principal auditory structures that appear in other figures. Shown are: inferior colliculus (IC), ventral nucleus of the lateral lemniscus (VNLL), dorsal nucleus of the lateral lemniscus (DNLL), central nucleus of the inferior colliculus (ICc), external nucleus of the inferior colliculus (ICx), dorsal nucleus of the inferior colliculus (ICd), and superior olivary complex (SOC). Numbers under each tissue section show the relative coordinates with respect to the landmark bregma on the rat skull. The schematic was adapted from Paxinos \& Watson (1998), used with permission from Elsevier. 


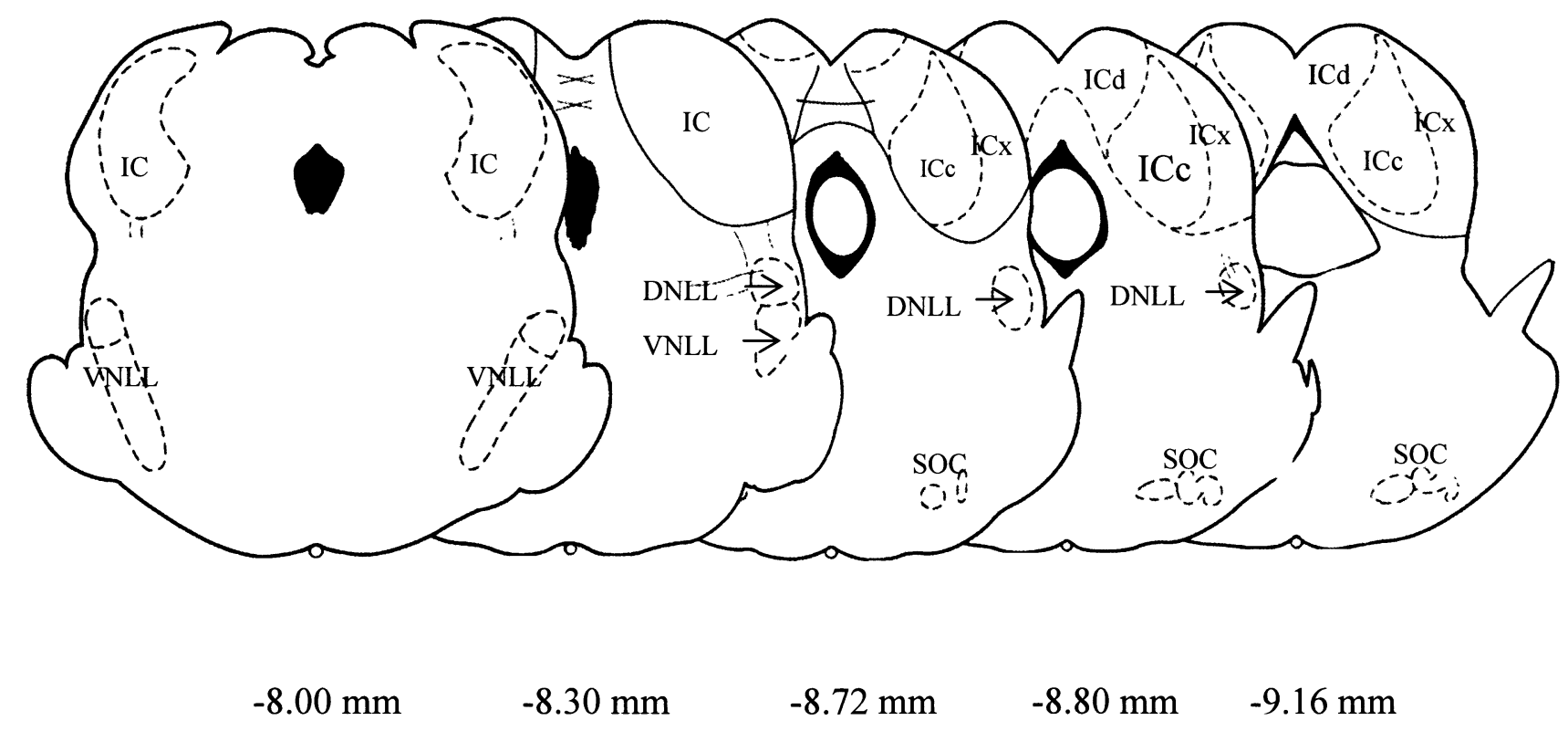


Figure 14: Typical partial and complete ICc lesions. The extent of a partial and complete lesion of the central nucleus of the inferior colliculus is shown here. A partial lesion is defined as a lesion that does not include the entire ICc. A complete lesion is a lesion which includes all of ICc. This figure was redrawn using photomicrographs of nissl sections of animal \# 14 (partial), and \# 37 (complete). For reference of structures, please see Figure 13. This schematic was redrawn from with permission from Elsevier from Paxinos \& Watson (1998). 


\section{Partial Lesion of ICc}

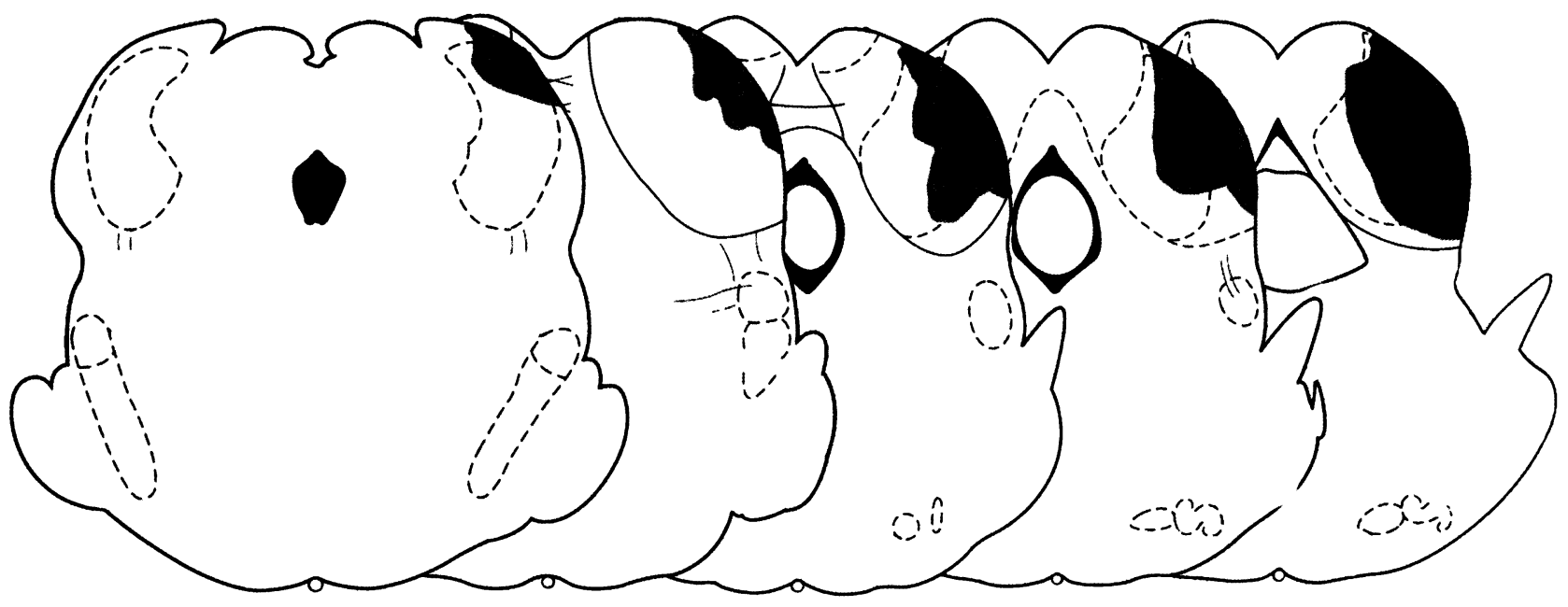

Animal \#14

\section{Complete Lesion of ICc}

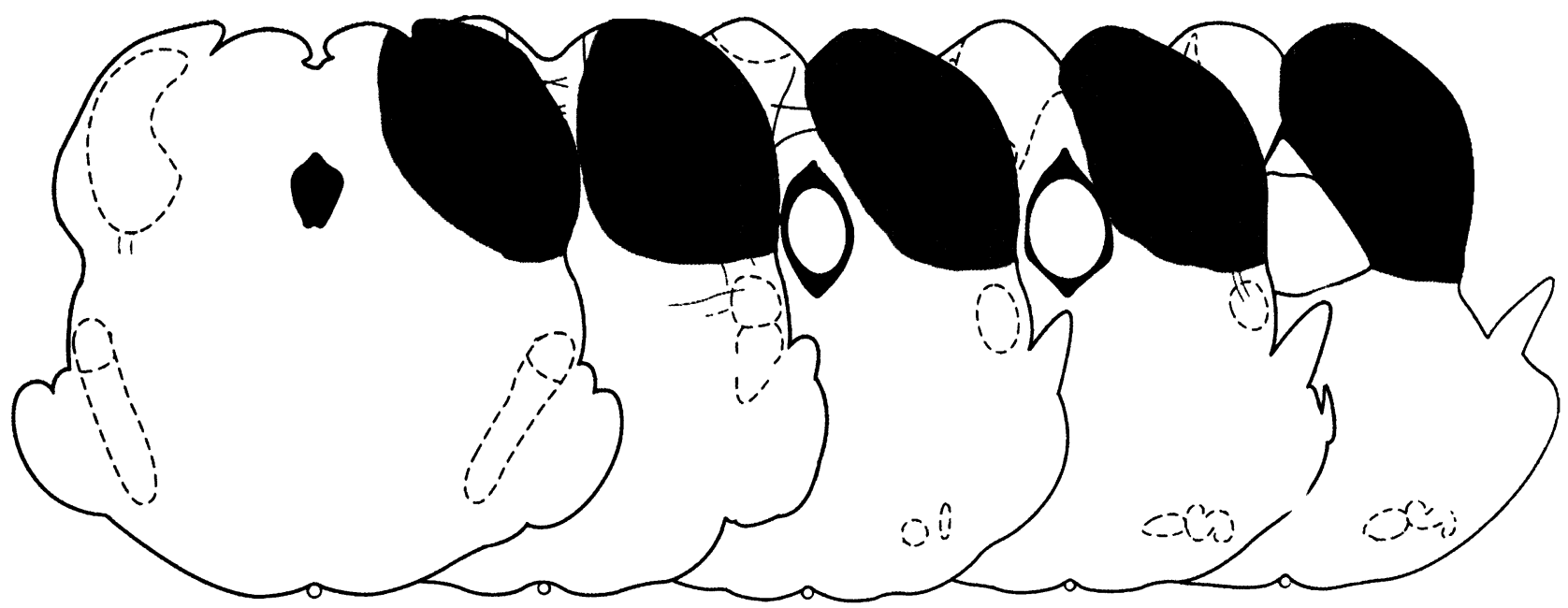

Animal \#37 
Figure 15: The pattern of retrograde labeling in DNLL, VNLL and SOC for normal animal after a unilateral injection of FG into the left ICc. FG labeling is shown in the ipsilateral (left) and contralateral (right) DNLL for a rat with FG in the left ICc (10x). Only the ipsilateral VNLL shows any retrograde labeling of FG (5x). The labeling in the SOC is apparent on the ipsilateral and contralateral sides; however the SOC on the contralateral side shows exclusive labeling in the LSO (10x). Photomicrographs are taken from animal \#41. Scale bar $=500 \mu \mathrm{m}$ in all photomicrographs. 
IPSILATERAL

DNLL
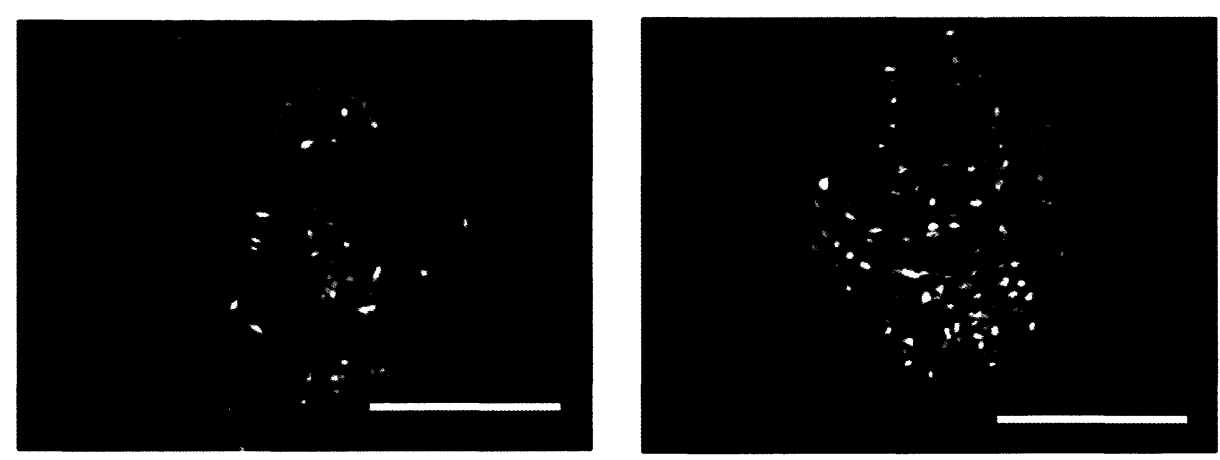

VNLL
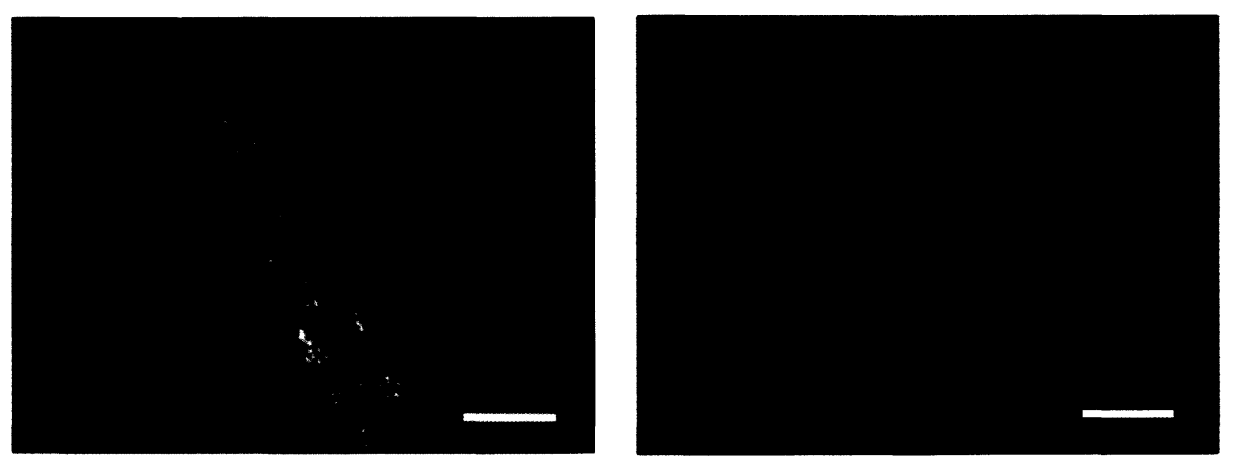

SOC

CONTRALATERAL
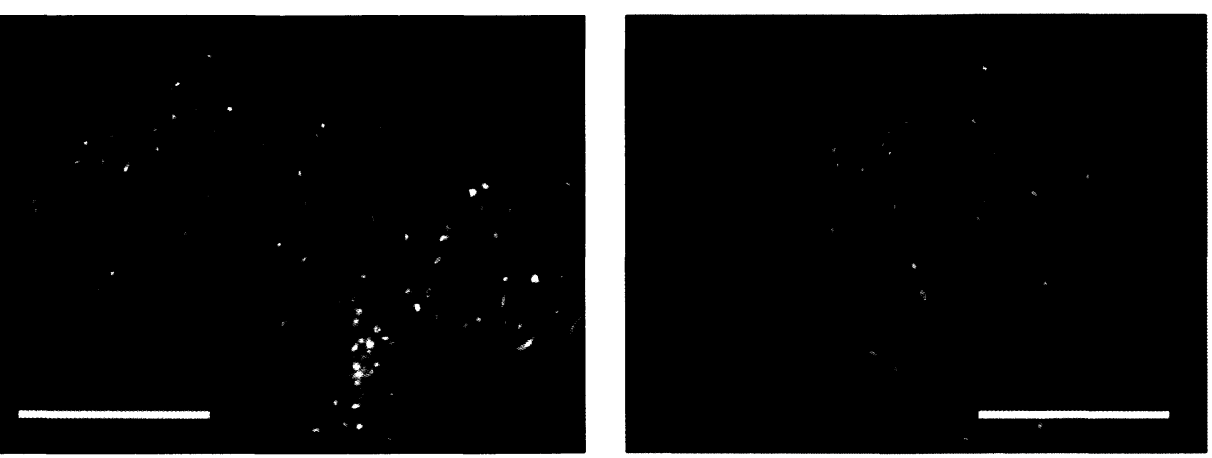
Figure 16: The pattern of retrograde labeling in the $\mathrm{CN}$ for a normal animal after a unilateral injection of FG into the left ICc. Note the relative absence of FG labeling in the AVCN, PCVN and DCN ipsilateral to the injection site. The cochlear nuclei

contralateral to the injection site all show extensive labeling. Photomicrographs are taken from animal \#41 (10x). Scale bar $=500 \mu \mathrm{m}$ in all photomicrographs. 
IPSILATERAL

AVCN
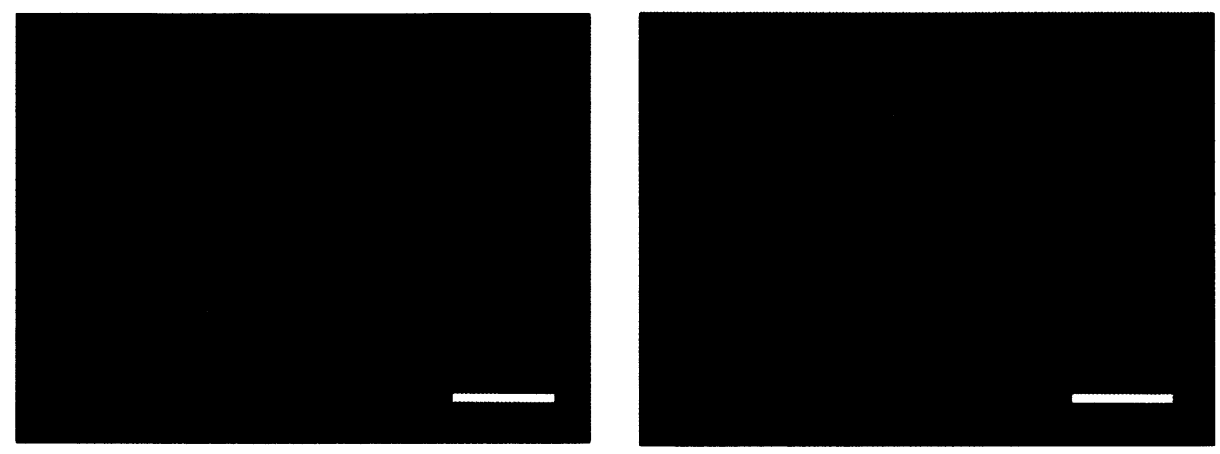

PVCN
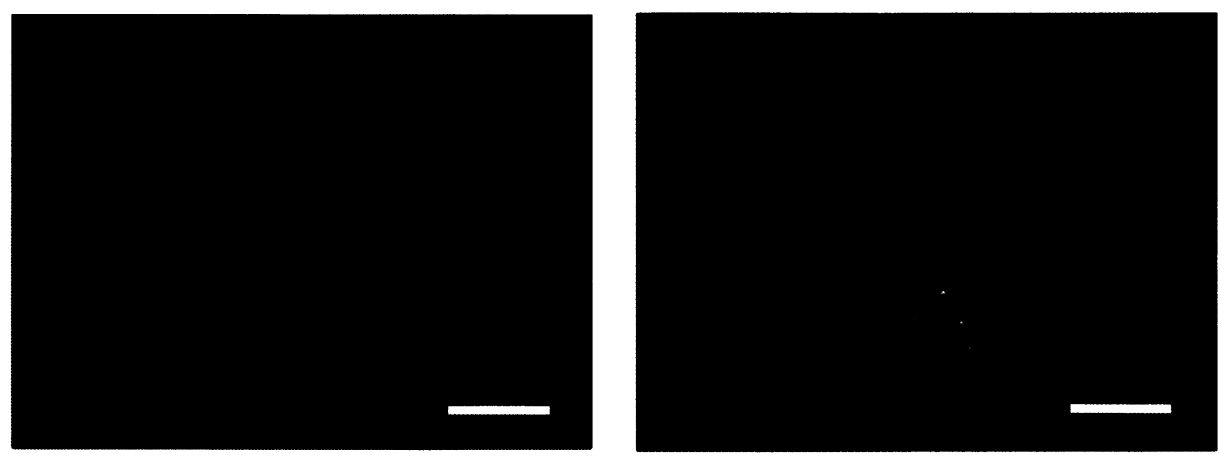

DCN

CONTRALATERAL
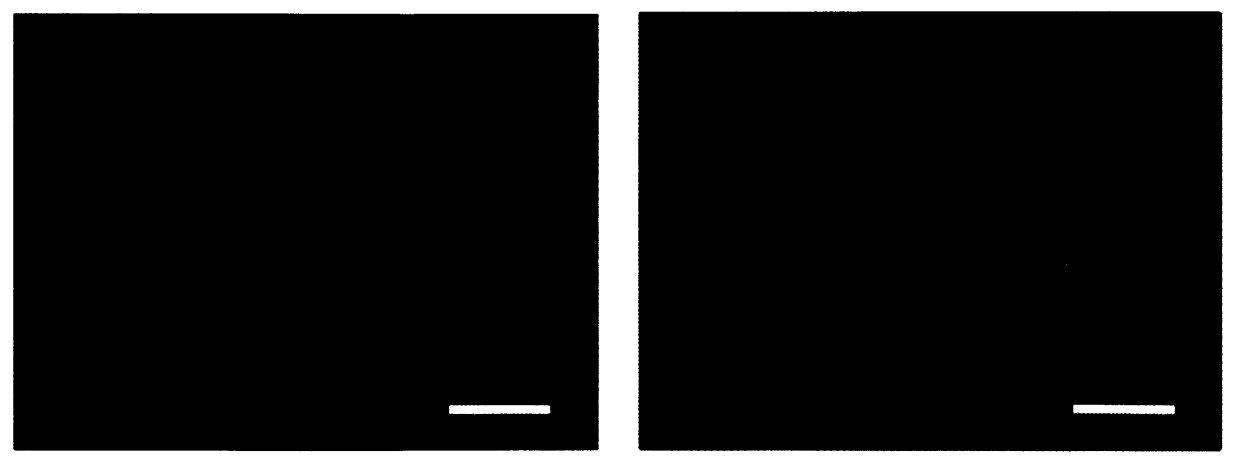
Figure 17: Retrograde FG labeling in an animal with a complete ICc lesion. (A): A photomicrograph reconstruction of retrograde FG labeling in an animal with a complete ICc lesion. Reconstruction was done at 5x magnification using Adobe Photoshop CS3. FG injection in the intact ICc of animal \#34 shows labeling in the ipsilateral DNLL and VNLL. The contralateral lesion of the IC does not extend to include the DNLL on the contralateral side. (B): A photomicrograph of the contralateral DNLL in nissl stain (10x). (C): A photomicrograph of the contralateral DNLL with FG labeling throughout the nucleus just below the destroyed ICc (10x). Photomicrographs B and C are taken from animal \# 36. Scale bar $=500 \mu \mathrm{m}$ in A and C (Scale in B is same as C). 
A

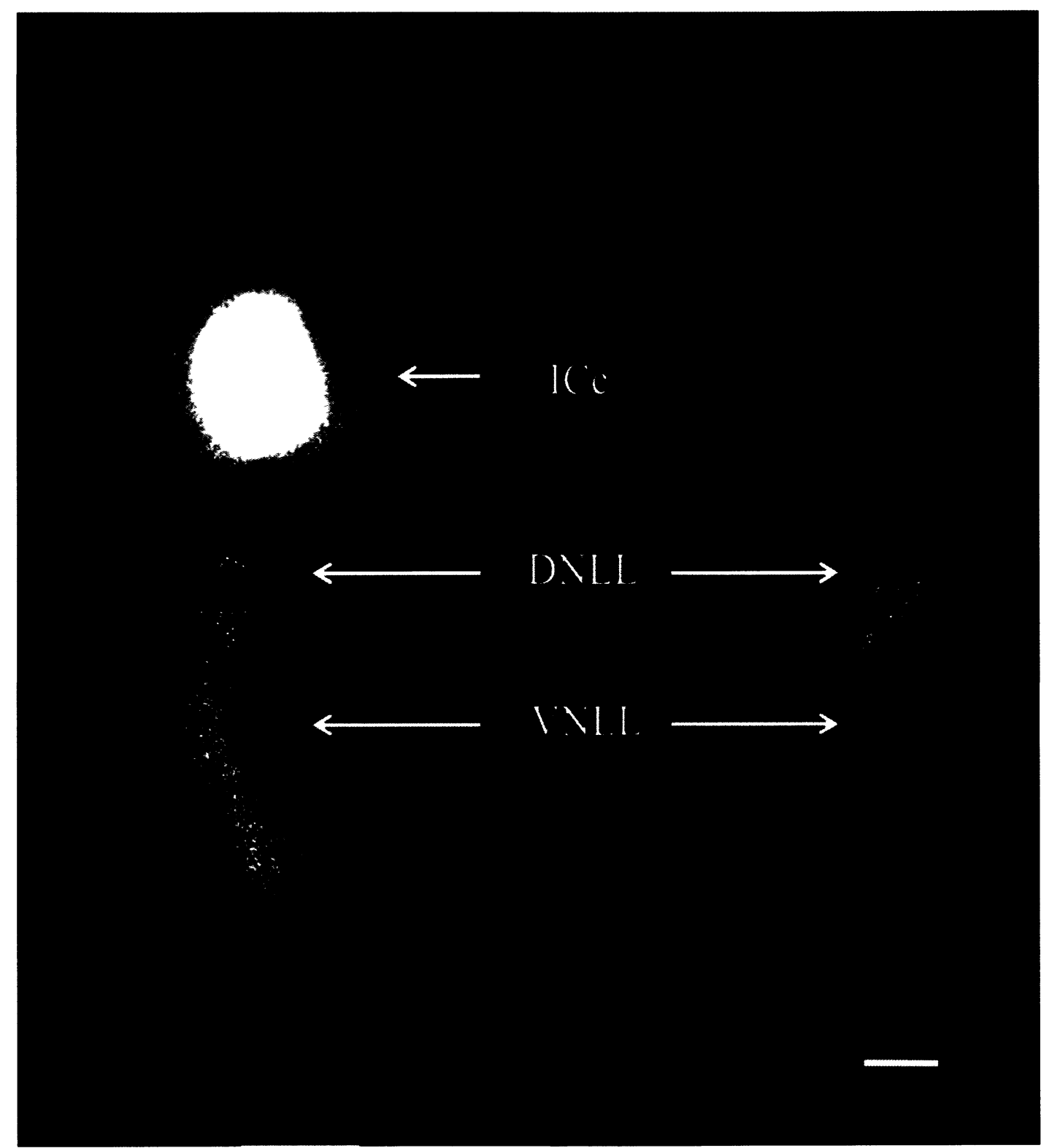

B

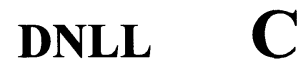

DNLL
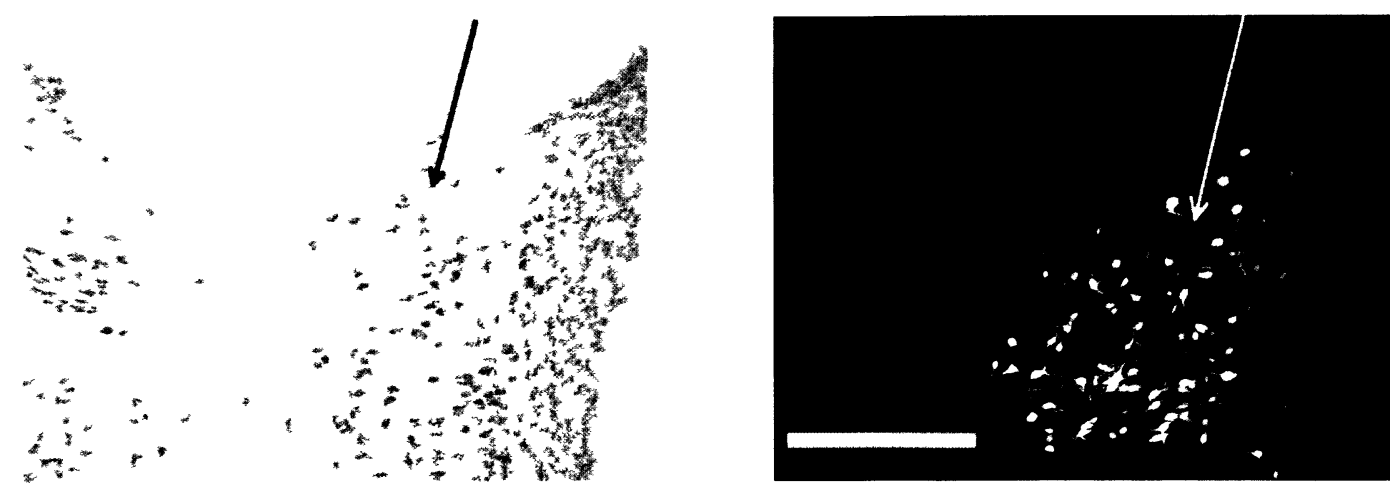
Figure 18: Plot of the mean absolute thresholds for each animal by lesion group.

Data show individual thresholds as well as the mean of each group \pm SD. Across groups, there was a significant difference in the mean thresholds as revealed by KruskalWallis ANOVA, $\chi_{(2, N=28)}^{2}=16.83, p=0.00$. Note that there is no difference between animals with ipsilateral lesions and normal animals (Mann-Whitney test, $Z=.893, p=$ .372). Animals with contralateral lesions are significantly different from normal animals (Mann-Whitney test, $Z=3.055, p=.001$ ) and those with ipsilateral lesions (MannWhitney test, $Z=3.408, p=.002)$. 


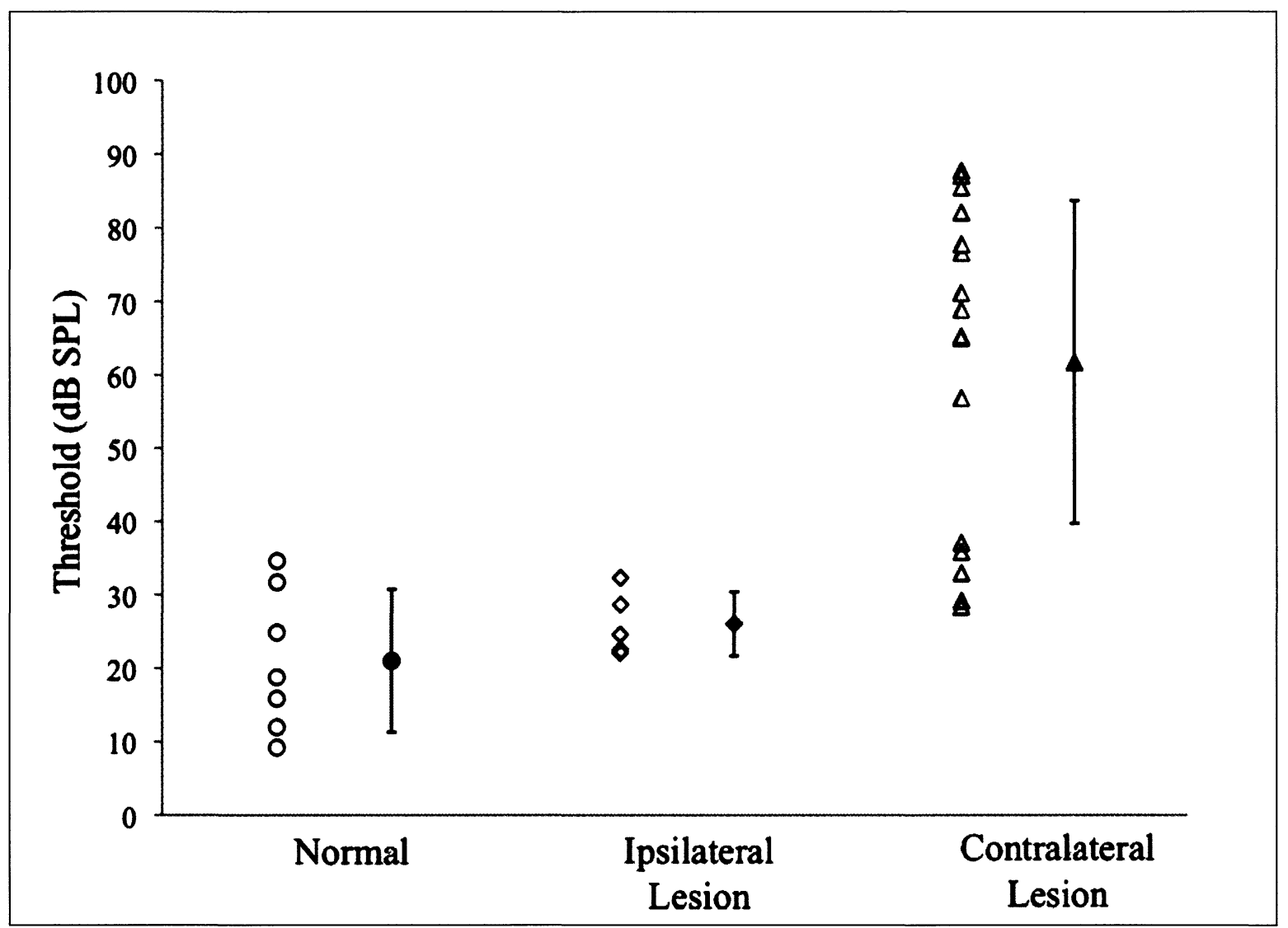


Figure 19: Plot of the mean absolute thresholds for animals with either ipsilateral or contralateral ICc lesions with respect to completeness of their lesion. Data show individual thresholds as well as the mean of each group $\pm \mathrm{SD}$. There was no difference between animals with complete or partial ipsilateral lesions of the ICc (Mann-Whitney test, $Z=1.732, p=.083)$. Animals with complete contralateral lesions had significantly higher thresholds than those with partial lesions (Mann-Whitney test, $Z=3.115, p=$ $.002)$. 


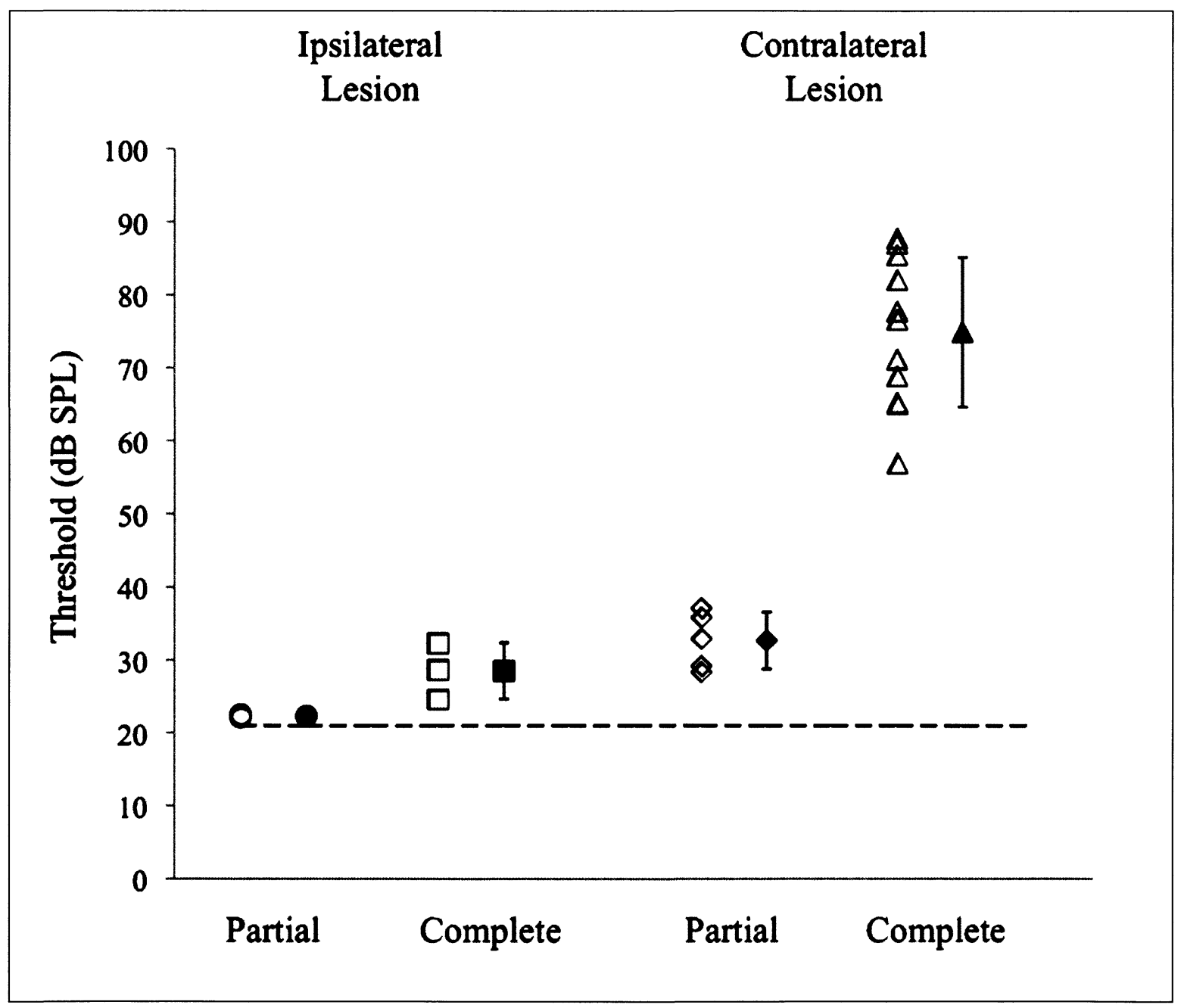


Figure 20: Plot of the mean absolute thresholds for animals with or without DNLL damage in addition to complete lesions of ICc. Data show individual thresholds as well as the mean of each group $\pm \mathrm{SD}$. With complete ipsilateral lesions of ICc there was no difference with or without damage to DNLL (Mann-Whitney test, $Z=1.225, p=$ .221). With complete contralateral lesions, however, animals with damage to DNLL had significantly higher thresholds than those without damage (Mann-Whitney test, $Z=$ $2.449, p=.014)$. 


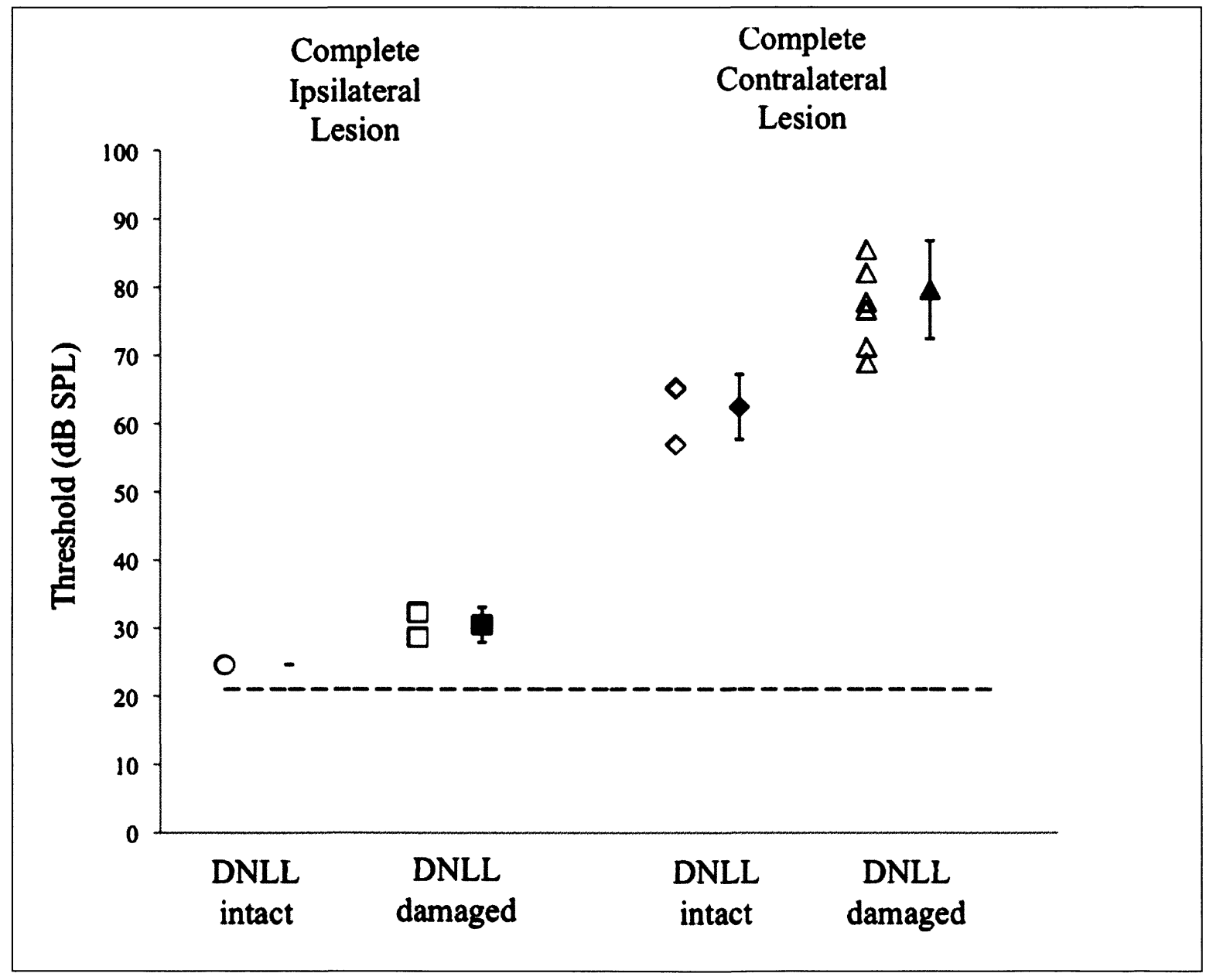




\section{References:}

Adams, J. C. (1979). Ascending projections to the inferior colliculus. J Comp Neurol, 183(3), 519-538.

Aitkin, L. M., \& Phillips, S. C. (1984). Is the inferior colliculus an obligatory relay in the cat auditory system? Neurosci Lett, 44(3), 259-264.

Alibardi, L. (1998). Ultrastructural and immunocytochemical characterization of neurons in the rat ventral cochlear nucleus projecting to the inferior colliculus. Ann Anat, 180(5), 415-426.

Batra, R., \& Fitzpatrick, D. C. (2002). Processing of interaural temporal disparities in the medial division of the ventral nucleus of the lateral lemniscus. $J$ Neurophysiol, 88(2), 666-675.

Bowen, G. P., Lin, D., Taylor, M. K., \& Ison, J. R. (2003). Auditory cortex lesions in the rat impair both temporal acuity and noise increment thresholds, revealing a common neural substrate. Cereb Cortex, 13(8), 815-822.

Browner, R. H., \& Webster, D. B. (1975). Projections of the trapezoid body and the superior olivary complex of the Kangaroo rat (Dipodomys merriami). Brain Behav Evol, 11(5-6), 322-354.

Brunso-Bechtold, J. K., Thompson, G. C., \& Masterton, R. B. (1981). HRP study of the organization of auditory afferents ascending to central nucleus of inferior colliculus in cat. J Comp Neurol, 197(4), 705-722.

Burke, A. J., \& Kelly, J. B. (2009). Functional Recovery in Gap Detection Following Bilateral Lesions of Auditory Cortex in the Rat ARO Abstracts 2009 (32 ed., pp. 36 - 37). Baltimore, Maryland.

Butler, A. B., \& Hodos, W. (1996). Comparative Vertebrate Neuroanatomy : Evolution and Adaptation. New York: John Wiley \& Sons.

Cant, N. B. (2005). Projections from Cochlear Nucleus to Inferior Colliculus. In J. A. Winer \& C. E. Schreiner (Eds.), The Inferior Colliculus (pp. 115 - 131). New York: Springer.

Casseday, J. H., Diamond, I. T., \& Harting, J. K. (1976). Auditory pathways to the cortex in Tupaia glis. J Comp Neurol, 166(3), 303-340.

Casseday, J. H., Fremouw, T., \& Covey, E. (2002). The inferior colliculus: hub of the auditory system. In D. Ortel, A. N. Popper \& F. R.R. (Eds.), Springer Handbook of Auditory Research (Vol. 15: Integrative Function in the Mammalian Auditory Pathway, pp. 238 - 318). New York: Springer. 
Casseday, J. H., \& Neff, W. D. (1975). Auditory localization: role of auditory pathways in brain stem of the cat. J Neurophysiol, 38(4), 842-858.

Casseday, J. H., Schreiner, C. E., \& Winer, J. A. (2005). Cytoarchitectonic views of the inferior colliculus in six common experimental species in Nissl Preparation. In J. A. Winer \& C. E. Schreiner (Eds.), The Inferior Colliculus (pp. 630). New York: Springer.

Clarkson, C., Lopez, D. E., \& Merchan, M. A. (2010). Long-term functional recovery in the rat auditory system after unilateral auditory cortex ablation. Acta Otolaryngol, 130(3), 326-332.

Clopton, B. M., \& Silverman, M. S. (1977). Plasticity of binaural interaction. II. Critical period and changes in midline response. J Neurophysiol, 40(6), 1275-1280.

Clopton, B. M., \& Winfield, J. A. (1973). Tonotopic organization in the inferior colliculus of the rat. Brain Res, 56, 355-358.

Coleman, J. R., \& Clerici, W. J. (1987). Sources of projections to subdivisions of the inferior colliculus in the rat. J Comp Neurol, 262(2), 215-226.

Davis, K. A. (2002). Evidence of a functionally segregated pathway from dorsal cochlear nucleus to inferior colliculus. J Neurophysiol, 87(4), 1824-1835.

Doron, N. N., \& LeDoux, J. E. (2000). Cells in the posterior thalamus project to both amygdala and temporal cortex: a quantitative retrograde double-labeling study in the rat. J Comp Neurol, 425(2), 257-274.

Faye-Lund, H. (1986). Projection from the inferior colliculus to the superior olivary complex in the albino rat. Anat Embryol (Berl), 175(1), 35-52.

Faye-Lund, H., \& Osen, K. K. (1985). Anatomy of the inferior colliculus in rat. Anat Embryol (Berl), 171(1), 1-20.

Fitzpatrick, K. A. (1975). Cellular architecture and topographic organization of the inferior colliculus of the squirrel monkey. J Comp Neurol, 164(2), 185-207.

Flammino, F. J., \& Clopton, B. M. (1975). Neural response in the inferior colliculus of the albino rat to binaural stimuli. Journal of the Acoustical Society of America(57), 692 - 695.

Frisina, R. D., Walton, J. P., Lynch-Armour, M. A., \& Klotz, D. A. (1997). Efferent projections of a physiologically characterized region of the inferior colliculus of the young adult CBA mouse. J Acoust Soc Am, 101(5 Pt 1), 2741-2753.

Galambos, R., Myers, R. E., \& Sheatz, G. C. (1961). Extralemniscal activation of auditory cortex in cats. Am J Physiol, 200, 23-28. 
Geniec, P., \& Morest, D. K. (1971). The neuronal architecture of the human posterior colliculus. A study with the Golgi method. Acta Otolaryngol Suppl, 295, 1-33.

Glendenning, K. K., Brunso-Bechtold, J. K., Thompson, G. C., \& Masterton, R. B. (1981). Ascending auditory afferents to the nuclei of the lateral lemniscus. $J$ Comp Neurol, 197(4), 673-703.

Glendenning, K. K., \& Hutson, K. A. (1998). Lack of topography in the ventral nucleus of the lateral lemniscus. Microsc Res Tech, 41(4), 298-312.

Glenn, S. L., \& Kelly, J. B. (1992). Kainic acid lesions of the dorsal nucleus of the lateral lemniscus: effects on binaural evoked responses in rat auditory cortex. J Neurosci, 12(9), 3688-3699.

Gonzalez-Hernandez, T., Mantolan-Sarmiento, B., Gonzalez-Gonzalez, B., \& PerezGonzalez, H. (1996). Sources of GABAergic input to the inferior colliculus of the rat. J Comp Neurol, 372(2), 309-326.

Heffner, H. E., \& Heffner, R. S. (1995). Conditioned Avoidance. In G. M. Klump, R.J.Dooling, R.R.Fay \& W.C.Stebbins (Eds.), Methods in Comparative Psychoacoustics (pp. 79-93). Switzerland: Birkhauser Verlag Basel.

Helfert, R. H., \& Aschoff, A. (1997). Superior olivary complex and nuclei of the lateral lemniscus. In G. Ehret \& R. Romand (Eds.), The Central Auditory System (pp. 193 - 258). New York: Oxford University Press.

Helfert, R. H., Snead, C. R., \& Altschuler, R. A. (1991). The ascending auditory pathways. In R. A. Altschuler, R. P. Bobbin, B. M. Clopton \& D. W. Hoffman (Eds.), Neurobiology of Hearing: The Central Auditory System (pp. 1 - 25). New York: Raven Press.

Hind, J. E., Goldberg, J. M., Greenwood, D. D., \& Rose, J. E. (1963). Some discharge characteristics of single neurons in the inferior colliculus of the cat. II. Timing of the discharges and observations on binaural stimulation. J Neurophysiol, $26,321-341$.

Huang, C. M., \& Fex, J. (1986). Tonotopic organization in the inferior colliculus of the rat demonstrated with the 2-deoxyglucose method. Exp Brain Res, 61(3), 506-512.

Huffman, R. F., \& Henson, O. W., Jr. (1990). The descending auditory pathway and acousticomotor systems: connections with the inferior colliculus. Brain Res Brain Res Rev, 15(3), 295-323.

Imig, T. J., \& Morel, A. (1984). Topographic and cytoarchitectonic organization of thalamic neurons related to their targets in low-, middle-, and high-frequency representations in cat auditory cortex. J Comp Neurol, 227(4), 511-539. 
Ison, J. R., O'Connor, K., Bowen, G. P., \& Bocirnea, A. (1991). Temporal resolution of gaps in noise by the rat is lost with functional decortication. Behav Neurosci, 105(1), 33-40.

Ito, M., Hatano, M., Okoyama, S., \& Kelly, J. B. (2008). Anatomical plasticity in brainstem auditory nuclei following unilateral ablation of the inferior colliculus in neonatal rats. Hear Res, 239(1-2), 92-98.

Ito, M., van Adel, B., \& Kelly, J. B. (1996). Sound localization after transection of the commissure of Probst in the albino rat. J Neurophysiol, 76(5), 3493-3502.

Jenkins, W. M., \& Masterton, R. B. (1982). Sound localization: effects of unilateral lesions in central auditory system. J Neurophysiol, 47(6), 987-1016.

Jenkins, W. M., \& Merzenich, M. M. (1984). Role of cat primary auditory cortex for sound-localization behavior. J Neurophysiol, 52(5), 819-847.

Kavanagh, G. L., \& Kelly, J. B. (1987). Contribution of auditory cortex to sound localization by the ferret (Mustela putorius). J Neurophysiol, 57(6), 17461766.

Kavanagh, G. L., \& Kelly, J. B. (1988). Hearing in the ferret (Mustela putorius): effects of primary auditory cortical lesions on thresholds for pure tone detection. $J$ Neurophysiol, 60(3), 879-888.

Kavanagh, G. L., \& Kelly, J. B. (1992). Midline and lateral field sound localization in the ferret (Mustela putorius): contribution of the superior olivary complex. $J$ Neurophysiol, 67(6), 1643-1658.

Kelly, J. B. (1980). Effects of auditory cortical lesions on sound localization by the rat. J Neurophysiol, 44(6), 1161-1174.

Kelly, J. B., \& Caspary, D. M. (2005). Inferior Colliculus Pharmacology. In J. A. Winer \& C. E. Schreiner (Eds.), The Inferior Colliculus (pp. 248 - 281). New York: Springer.

Kelly, J. B., \& Glazier, S. J. (1978). Auditory cortex lesions and discrimination of spatial location by the rat. Brain Res, 145(2), 315-321.

Kelly, J. B., Glenn, S. L., \& Beaver, C. J. (1991). Sound frequency and binaural response properties of single neurons in rat inferior colliculus. Hear Res, 56(1-2), 273280.

Kelly, J. B., \& Judge, P. W. (1985). Effects of medial geniculate lesions on sound localization by the rat. J Neurophysiol, 53(2), 361-372. 
Kelly, J. B., Judge, P. W., \& Phillips, D. P. (1986). Representation of the cochlea in primary auditory cortex of the ferret (Mustela putorius). Hear Res, 24(2), 111-115.

Kelly, J. B., \& Kavanagh, G. L. (1986). Effects of auditory cortical lesions on pure-tone sound localization by the albino rat. Behav Neurosci, 100(4), 569-575.

Kelly, J. B., \& Kavanagh, G. L. (1994). Sound localization after unilateral lesions of inferior colliculus in the ferret (Mustela putorius). J Neurophysiol, 71(3), 1078-1087.

Kelly, J. B., \& Kidd, S. A. (2000). NMDA and AMPA receptors in the dorsal nucleus of the lateral lemniscus shape binaural responses in rat inferior colliculus. $J$ Neurophysiol, 83(3), 1403-1414.

Kelly, J. B., \& Li, L. (1997). Two sources of inhibition affecting binaural evoked responses in the rat's inferior colliculus: the dorsal nucleus of the lateral lemniscus and the superior olivary complex. Hear Res, 104(1-2), 112-126.

Kelly, J. B., Li, L., \& van Adel, B. (1996). Sound localization after kainic acid lesions of the dorsal nucleus of the lateral lemniscus in the albino rat. Behav Neurosci, $110(6), 1445-1455$.

Kelly, J. B., Rooney, B. J., \& Phillips, D. P. (1996). Effects of bilateral auditory cortical lesions on gap-detection thresholds in the ferret (Mustela putorius). Behav Neurosci, 110(3), 542-550.

Kelly, J. B., \& Sally, S. L. (1988). Organization of auditory cortex in the albino rat: binaural response properties. J Neurophysiol, 59(6), 1756-1769.

Kelly, J. B., van Adel, B. A., \& Ito, M. (2009). Anatomical projections of the nuclei of the lateral lemniscus in the albino rat (Rattus norvegicus).J Comp Neurol, 512(4), 573-593.

Kelly, J. B., \& Zhang, H. (2002). Contribution of AMPA and NMDA receptors to excitatory responses in the inferior colliculus. Hear Res, 168(1-2), 35-42.

Kidd, S. A., \& Kelly, J. B. (1996). Contribution of the dorsal nucleus of the lateral lemniscus to binaural responses in the inferior colliculus of the rat: interaural time delays. J Neurosci, 16(22), 7390-7397.

Kitzes, L. M., Wrege, K. S., \& Cassady, J. M. (1980). Patterns of responses of cortical cells to binaural stimulation. J Comp Neurol, 192(3), 455-472.

Knudsen, E. I., \& Konishi, M. (1978). A neural map of auditory space in the owl. Science, 200(4343), 795-797. 
LeDoux, J.E. (2003). The emotional brain, fear, and the amygdala. Cell Mol Neurobiol, 23(4-5), 727-738.

Li, L., \& Kelly, J. B. (1992). Inhibitory influence of the dorsal nucleus of the lateral lemniscus on binaural responses in the rat's inferior colliculus. J Neurosci, 12(11), 4530-4539.

Lim, H. H., Lenarz, T., Joseph, G., Battmer, R. D., Samii, A., Samii, M., et al. (2007). Electrical stimulation of the midbrain for hearing restoration: insight into the functional organization of the human central auditory system. J Neurosci, 27(49), 13541-13551.

Malmierca, M. S., Blackstad, T. W., Osen, K. K., Karagulle, T., \& Molowny, R. L. (1993). The central nucleus of the inferior colliculus in rat: a Golgi and computer reconstruction study of neuronal and laminar structure. J Comp Neurol, 333(1), 1-27.

Malmierca, M. S., Izquierdo, M. A., Cristaudo, S., Hernandez, 0., Perez-Gonzalez, D., Covey, E., et al. (2008). A discontinuous tonotopic organization in the inferior colliculus of the rat. J Neurosci, 28(18), 4767-4776.

Malmierca, M. S., \& Merchán, M. A. (2004). Auditory System. In G. Paxinos (Ed.), The Rat Nervous System (pp. 999). San Diego: Academic Press.

Malmierca, M. S., Rees, A., \& LeBeau, F. E. N. (1997). Ascending projections to the medial geniculate body from physiologically identified loci in the inferior colliculus. In J. Syka (Ed.), Acoustic Aignal Processing in the Central Auditory System (pp. 295 - 302). New York: Plenum Press.

Masterton, R. B., \& Imig, T. J. (1984). Neural mechanisms for sound localization. Annu Rev Physiol, 46, 275-287.

Masterton, R. B., Jane, J. A., \& Diamond, I. T. (1968). The role of brainstem auditory structures in sound localization. II. Inferior colliculus and its brachium. Journal of Neurophysiology(31), 96 - 108.

Merzenich, M. M., \& Reid, M. D. (1974). Representation of the cochlea within the inferior colliculus of the cat. Brain Res, 77(3), 397-415.

Moore, C. N., Casseday, J. H., \& Neff, W. D. (1974). Sound localization: the role of the commissural pathways of the auditory system of the cat. Brain Res, 82(1), 1326.

Morest, D. K. (1964). The laminar structure of the inferior colliculus of the cat. Anat $\operatorname{Rec}, 148,314$. 
Morest, D. K., \& Oliver, D. L. (1984). The neuronal architecture of the inferior colliculus in the cat: defining the functional anatomy of the auditory midbrain. J Comp Neurol, 222(2), 209-236.

Morest, D. K., \& Winer, J. A. (1986). The comparative anatomy of neurons: homologous neurons in the medial geniculate body of the opossum and the cat. Adv Anat Embryol Cell Biol, 97, 1-94.

Neff, W. D., \& Casseday, J. H. (1977). Effects of unilateral ablation of auditory cortex on monaural cat's ability to localize sound. J Neurophysiol, 40(1), 44-52.

Nieder, P. C., \& Strominger, N. L. (1965). Evoked potentials in auditory cortex after bilateral transection of the brachium of the inferior colliculus in the cat. $J$ Neurophysiol, 28(6), 1185-1194.

Nordeen, K. W., Killackey, H. P., \& Kitzes, L. M. (1983). Ascending auditory projections to the inferior colliculus in the adult gerbil, Meriones unguiculatus. J Comp Neurol, 214(2), 131-143.

Okoyama, S., Moriizumi, T., Kitao, Y., Kawano, J., \& Kudo, M. (1995a). Anatomical plasticity in the medial superior olive following ablation of the inferior colliculus in neonatal and adult rats. Hear Res, 88(1-2), 71-78.

Okoyama, S., Moriizumi, T., Kitao, Y., Kawano, J., \& Kudo, M. (1995b). Postnatal development of the projection from the medial superior olive to the inferior colliculus in the rat. Hear Res, 88(1-2), 65-70.

Oliver, D. L. (1984a). Dorsal cochlear nucleus projections to the inferior colliculus in the cat: a light and electron microscopic study. J Comp Neurol, 224(2), 155172.

Oliver, D. L. (1984b). Neuron types in the central nucleus of the inferior colliculus that project to the medial geniculate body. Neuroscience, 11(2), 409-424.

Oliver, D. L. (2005). Neuronal organization in the inferior colliculus. In J. A. Winer \& C. E. Schreiner (Eds.), The Inferior Collicuus (pp. 69 - 114). New York: Springer.

Oliver, D. L., \& Morest, D. K. (1984). The central nucleus of the inferior colliculus in the cat. J Comp Neurol, 222(2), 237-264.

Ortel, D., \& Wickesberg, D. E. (2002). Ascending pathways through ventral nuclei of the lateral lemniscus and their possible role in pattern recognition in natural sounds. In D. Ortel, A. N. Popper \& F. R.R. (Eds.), Springer Handbook of Auditory Research (Vol. 15: Integrative Function in the Mammalian Auditory Pathway, pp. 207 - 237). New York: Springer. 
Osen, K. K. (1972). Projection of the cochlear nuclei on the inferior colliculus in the cat. Journal of Comparative Neurology, 144(0021-9967 (Print)), 355 - 372.

Papez, J. W. (1929). Central acoustic tract in cat and man. Anatomical Records, 42(60).

Paxinos, G., \& Watson, C. (1998). The rat brain in stereotaxic coordinates (4th ed.). San Diego: Academic Press.

Phillips, D. P., \& Irvine, D. R. (1981). Responses of single neurons in physiologically defined area AI of cat cerebral cortex: sensitivity to interaural intensity differences. Hear Res, 4(3-4), 299-307.

Ramón y Cajal, S. (1909). Histologie du système nerveux de l'homme et des vértébrates (A. L. Maloine, Trans.). Madrid, Spain: Consejo Superior de Investigaciones Científicas.

Rockel, A. J., \& Jones, E. G. (1973a). The neuronal organization of the inferior colliculus of the adult cat. I. The central nucleus. J Comp Neurol, 147(1), 1160 .

Rockel, A. J., \& Jones, E. G. (1973b). The neuronal organization of the inferior colliculus of the adult cat. II. The pericentral nucleus. J Comp Neurol, 149(3), 301-334.

Romand, R., \& Avan, P. (1997). Anatomical and functional aspects of the cochlear nucleus. In G. Ehret \& R. Romand (Eds.), The Central Auditory System (pp. 97 192). New York: Oxford University Press.

Rose, J. E., Gross, N. B., Geisler, C. D., \& Hind, J. E. (1966). Some neural mechanisms in the inferior colliculus of the cat which may be relevant to localization of a sound source. J Neurophysiol, 29(2), 288-314.

Roth, G. L., Aitkin, L. M., Andersen, R. A., \& Merzenich, M. M. (1978). Some features of the spatial organization of the central nucleus of the inferior colliculus of the cat. J Comp Neurol, 182(4), 661-680.

Ryugo, D. K., Willard, F. H., \& Fekete, D. M. (1981). Differential afferent projections to the inferior colliculus from the cochlear nucleus in the albino mouse. Brain Res, 210(1-2), 342-349.

Saint Marie, R. L., \& Baker, R. A. (1990). Neurotransmitter-specific uptake and retrograde transport of $[3 \mathrm{H}]$ glycine from the inferior colliculus by ipsilateral projections of the superior olivary complex and nuclei of the lateral lemniscus. Brain Res, 524(2), 244-253. 
Saint Marie, R. L., Luo, L., \& Ryan, A. F. (1999). Spatial representation of frequency in the rat dorsal nucleus of the lateral lemniscus as revealed by acoustically induced c-fos mRNA expression. Hear Res, 128(1-2), 70-74.

Sally, S. L., \& Kelly, J. B. (1992). Effects of superior olivary complex lesions on binaural responses in rat inferior colliculus. Brain Res, 572(1-2), 5-18.

Schofield, B. R. (2005). Olivary and Lemniscal Projections. In J. A. Winer \& C. E. Schreiner (Eds.), The Inferior Colliculus (pp. 132 - 154). New York: Springer.

Schreiner, C. E., \& Langner, G. (1997). Laminar fine structure of frequency organization in auditory midbrain. Nature, 388(6640), 383-386.

Semple, M. N., \& Aitkin, L. M. (1979). Representation of sound frequency and laterality by units in central nucleus of cat inferior colliculus. J Neurophysiol, 42(6), 1626-1639.

Shneiderman, A., Oliver, D. L., \& Henkel, C. K. (1988). Connections of the dorsal nucleus of the lateral lemniscus: an inhibitory parallel pathway in the ascending auditory system? J Comp Neurol, 276(2), 188-208.

Sivaramakrishnan, S., \& Oliver, D. L. (2001). Distinct K currents result in physiologically distinct cell types in the inferior colliculus of the rat. $J$ Neurosci, 21(8), 2861-2877.

Starzl, T. E., Taylor, C. W., \& Magoun, H. W. (1951). Collateral afferent excitation of reticular formation of brain stem. J Neurophysiol, 14(6), 479-496.

Strominger, N. L., \& Oesterreich, R. E. (1970). Localization of sound after section of the brachium of the inferior colliculus. J Comp Neurol, 138(1), 1-18.

Strominger, N. L., \& Strominger, A. I. (1971). Ascending brain stem projections of the anteroventral cochlear nucleus in the rhesus monkey. J Comp Neurol, 143(2), 217-242.

Syka, J., Rybalko, N., Mazelova, J., \& Druga, R. (2002). Gap detection threshold in the rat before and after auditory cortex ablation. Hear Res, 172(1-2), 151-159.

Takahashi, T. T., \& Konishi, M. (1988). Projections of nucleus angularis and nucleus laminaris to the lateral lemniscal nuclear complex of the barn owl. J Comp Neurol, 274(2), 212-238.

Thompson, G. C., \& Cortez, A. M. (1983). The inability of squirrel monkeys to localize sound after unilateral ablation of auditory cortex. Behav Brain Res, 8(2), 211216. 
Thompson, G. C., Cortez, A. M., \& Lam, D. M. (1985). Localization of GABA immunoreactivity in the auditory brainstem of guinea pigs. Brain Res, 339(1), 119-122.

van Adel, B. A., Kidd, S. A., \& Kelly, J. B. (1999). Contribution of the commissure of Probst to binaural evoked responses in the rat's inferior colliculus: interaural time differences. Hear Res, 130(1-2), 115-130.

Warr, W. B. (1966). Fiber degeneration following lesions in the anterior ventral cochlear nucleus of the cat. Exp Neurol, 14(4), 453-474.

Wenstrup, J. J. (2005). The Tectothalamic System. In J. A. Winer \& C. E. Schreiner (Eds.), The Inferior Colliculus (pp. 200 - 230). New York: Springer.

Willard, F. H., \& Martin, G. F. (1983). The auditory brainstem nuclei and some of their projections to the inferior colliculus in the North American opossum. Neuroscience, 10(4), 1203-1232.

Willard, F. H., \& Ryugo, D. K. (1983). Anatomy of the central auditory system. In J. F. Willott (Ed.), The Auditory psychobiology of the mouse (pp. 201-304). Springfield, Illinois: Charles C Thomas Publishing Company.

Winer, J. A., Larue, D. T., Diehl, J. J., \& Hefti, B. J. (1998). Auditory cortical projections to the cat inferior colliculus. J Comp Neurol, 400(2), 147-174.

Winer, J. A., \& Schreiner, C. E. (2005). The Central Auditory System: A Functional Analysis. In J. A. Winer \& C. E. Schreiner (Eds.), The Inferior Colliculus (pp. 168). New York: Springer.

Zhang, D. X., Li, L., Kelly, J. B., \& Wu, S. H. (1998). GABAergic projections from the lateral lemniscus to the inferior colliculus of the rat. Hear Res, 117(1-2), 1-12.

Zook, J. M., \& Casseday, J. H. (1982). Origin of ascending projections to inferior colliculus in the mustache bat, Pteronotus parnellii. J Comp Neurol, 207(1), 14-28.

Zook, J. M., Winer, J. A., Pollak, G. D., \& Bodenhamer, R. D. (1985). Topology of the central nucleus of the mustache bat's inferior colliculus: correlation of single unit properties and neuronal architecture. J Comp Neurol, 231(4), 530-546.

Zrull, M. C., \& Coleman, J. R. (1999). Spatial sound detection and the role of the inferior colliculus in the Long-Evans rat. Acta Otolaryngol, 119(3), 326-332. 